\title{
Synthesis and Characterization of Platinum and Platinum based Alloy Nanoparticles Anchored on Various Carbon Materials for Methanol Oxidation in a DMFC - A Short Review
}

\author{
Richa Baronia', Jyoti Goel ${ }^{2}$ and Sunil K. Singhal2,** \\ ${ }^{1}$ AcSIR-Academy of Scientific \& Innovative Research, Council of Scientific \& Industrial Research (CSIR) \\ ${ }^{2}$ CSIR-National Physical Laboratory, Dr. K.S. Krishnan Marg, New Delhi 110012, India \\ *Corresponding authors: E-mail: singhalsk66@gmail.com
}

DOI: 10.5185/amlett.2021.041617

In the fabrication of direct methanol fuel cells (DMFCs) having high performance the essential conditions are (i) the design and construction of a suitable anode electrocatalyst comprising of Pt or a Pt based alloy nanoparticles methanol oxidation reaction (MOR) efficiently and effectively (ii) nature of support materials onto which these nanoparticles are anchored. In MOR one of the major problems is the adsorption of poisoneous carbonmoxide and other similar intermediates near the active surface of $\mathrm{Pt}$ active leading to its deactivation and also the crossover of methanol solution towards the cathodic side. All these factors, therefore, lower the overall electrochemical performance of the electro-catalysts. In the present review paper we report some of our important results of the synthesis of different Pt and Pt based anode electro-catalysts (Pt, PtCo alloys, PtCu alloys) anchored on different support materials such as reduced graphene oxide ( $\mathrm{rCO}$ ), Nitrogen doped rGO and a hybrid of rGO/CNTs for MOR and compared with few of those already reported recently. A detailed characterization of raw materials and the electro-catalysts synthesized in this work is also discussed using XRD, FT-IR, SEM, TEM etc. The electrochemical measurements were made using cyclic voltammetry in acidic medium at room temperature.

\section{Introduction}

In the last few years much attention has been paid on the development of direct methanol fuel cells (DMFCs) because of their use as power source in many of electronic devices including mobile phones, laptop and other applications $[\mathbf{1 , 2}]$. The main advantages of DMFCs are that they provide clean power source for these devices, light weight and operate at lower temperatures. In these fuel cells, aqueous methanol used as a fuel is electrochemically oxidized and converted into electricity without burning. The oxidation of methanol in a DMFC is occurred at the anode and it undergoes electro-oxidation to $\mathrm{CO}_{2}$ through the following reaction:

$$
\mathrm{CH}_{3} \mathrm{OH}+\mathrm{H}_{2} \rightarrow \mathrm{CO}_{2}+6 \mathrm{H}^{+}+6 \mathrm{e}^{-}
$$

While the protons produced at the anode side reacts with $\mathrm{O}_{2}$ at the cathode producing $\mathrm{H}_{2} \mathrm{O}$.

$$
3 / 2 \mathrm{O}_{2}+6 \mathrm{H}^{+}+6 \mathrm{e}^{-} \rightarrow 3 \mathrm{H}_{2} \mathrm{O}
$$

The overall reactions are written as:

$$
\mathrm{CH}_{3} \mathrm{OH}+3 / 2 \mathrm{O}_{2} \rightarrow \mathrm{CO}_{2}+2 \mathrm{H}_{2} \mathrm{O}
$$

The protons $\left(\mathrm{H}^{+}\right)$generated at the anode move towards the cathode through a thin proton exchange membrane (PEM) normally made from Nafion 117 solution and react with the $\mathrm{O}_{2}$ at the cathode and the electricity is produced. It is well known that $\mathrm{Pt}$ is one of the best anodes electrocatalysts for the oxidation of methanol solution. However, its application for practical purposes is not promising because of its high price and it is believed that only Pt accounts for nearly $40-50 \%$ total cost of the fuel cell. Further, the other challenges in the development of these DMFCs are to increase their electrochemical stability, high efficiency and to provide a high-power density. These challenges are usually met by fabricating a anode comprising of Pt or Pt-based deposited homogeneously on nanostructured materials including carbon [3,4], multiwalled carbon nanotubes (CNTs) [510], carbon nanofibers $(\mathrm{CNFs})[\mathbf{1 1 , 1 2}]$, reduced graphene oxide (rGO) [13-26], expanded graphite [27,28], graphitic form of carbon nitride $\left(\mathrm{g}-\mathrm{C}_{3} \mathrm{~N}_{4}\right)$ [29-32] and nitrogendoped rGO or CNTs [33-37] etc. All of these results have shown the enhanced electrochemical behavior of these electrocatalysts in comparison to that of commercial Pt/C. Out of various support materials as mentioned above, graphene or rGO based support materials have attracted a major attention because of its excellent properties including higher electrical conductivity, larger specific surface area $\left(2600 \mathrm{~m}^{2} / \mathrm{g}\right)$ and various other properties [3840]. However, one of the major proble, s using pure rGO is the agglomeration of these nanosheets in solutions because of the strong interaction between the individual nanosheets [41]. Thus, because of this agglomeration, these reduced graphene nanosheets do not have properties that exhibited by pure graphene. Therefore, in order to utilize the excellent properties of graphene rGO 


\section{Advanced Materials Letters www.vbripress.com/aml}

nanosheets are either acid functionalized [42-44] or some other conducting materials e.g., carbon nanotubes etc. are introduced between the graphene nanosheets $[\mathbf{4 5 , 4 6 ]}$. Similarly, pure carbon nanotubes have no functional groups for anchoring metal nanoparticles. Therefore, in order to enhance their bonding with the metal nanoparticles they are also acid functionalized by treating them with a mixture of $\mathrm{H}_{2} \mathrm{SO}_{4}$ and $\mathrm{HNO}_{3}$ or some other functionalized materials including oxygen, $S$ or conducting polymers [47-51]. Recently N-doped rGO, CNTs and graphene modified by $\mathrm{N}$ doped $\mathrm{C}$ etc have been used as excellent materials for the anchoring of metal nanoparticles owing to strong metal-support interaction induced by $\mathrm{N}$ groups [52-58]. In all these support materials Pt and its alloys are anchored for the fabrication of anode for methanol electron oxidation (MOR) in acidic or alkaline medium. Although Pt is considered to be most suitable for MOR, one of the major problems encountered using pure Pt catalysts is that it is very expensive to be commercially available. Further its surface is deactivated easily due to the adsorption of carbon monoxide (CO) and various other carbonaceous thereby blocking the active sites $[\mathbf{5 9 , 6 0}]$. The possible reactions taking place during the MOR are shown in Fig. 1 as recently reported [61].

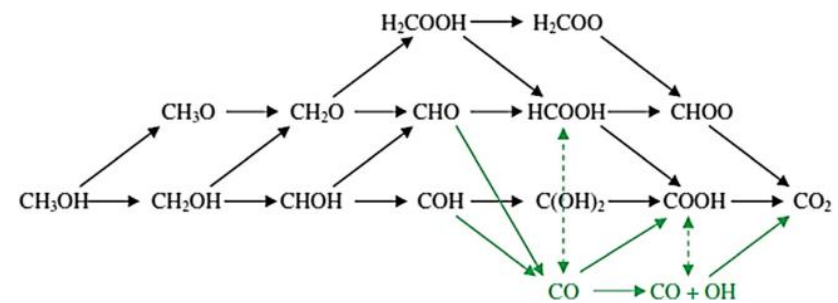

Fig. 1. Possible intermediates formed during MOR through various reactions [61].

Thus, there is need to investigate an alloy of Pt with some other nanoparticles which not only minimize the adsorption of $\mathrm{CO}$ from the surface of Pt sites and convert into $\mathrm{CO}_{2}$ but also improve the electrochemical surface area, homogeneous dispersion and enhance the electrooxidation of methanol using the bifunctional mechanism $[6,61,62]$. According to this theory, the adsorption of hydroxyl species during methanol electro-oxidation solution adsorb on the second metal alloyed with $\mathrm{Pt}$ because of its oxophyllic nature, thereby minimizing the adsorption of $\mathrm{CO}$ from the active $\mathrm{Pt}$ sites for the enhancement of MOR. Further, because of strong bonding between the support and metal nanoparticles, the overall electrochemical activity of the electrocatalyst also increases for methanol oxidation. Therefore, in order to minimize the deactivation of $\mathrm{Pt}$, its electronic characteristic is changed by alloying it with some other metals. The catalytic activity and stability of the present electrocatalysts still requires more research work for the commercialization of DMFCs. In the research work carried out so far, $\mathrm{Pt}$ is alloyed with some other metals to minimize the adsorption of $\mathrm{CO}$ for the active sites of $\mathrm{Pt}$ and promote MOR at lower potentials with its minimum usage. The essential parameter for these catalysts is they should have the large electrochemical surface area, homogeneous dispersion on support materials, more favorable Pt-Pt distance should be able to remove $\mathrm{CO}$ from the Pt surface. It has been found that best results towards MOR are obtained if $\mathrm{Pt}$ is alloyed with 3-d transition metals ( $\mathrm{Fe}, \mathrm{Co}, \mathrm{Ni}, \mathrm{Pd}, \mathrm{Cu})[\mathbf{6 , 1 9 , 6 3 - 6 8}]$ etc as well as $\mathrm{Ru}$ and $\mathrm{Pd}[\mathbf{5 , 4 7 , 6 8 - 7 0 ]}$ in different compositions deposited homogeneously on a number of support materials as mentioned above. Although among the bimetallic alloys of $\mathrm{Pt}, \mathrm{PtRu}$ has catalyst has been found to exhibit much better electrochemical behavior towards methanol oxidation, the supply of Ru is also very limited [13]. Recently, it has been reported the use of ultrathin Iridium (Ir) nanosheets as a class of mesoporous 2D metals for their excellent electrochemical behavior towards oxygen evolution reaction (EOR) because of their higher surface area and more reaction sites are available [71]. The mesoporous Ir metal nanosheets electrocatalyst not only exhibits better EOR but it can operate at low overpotentials, still maintaining high stability and a better resistance to $\mathrm{CO}$ poisioning. Similarly, in the class of mesoporous 2D metals, mesoporous Pd nanoparticles with tunable pore constructions have been shown to perform excellent electrocatalytic activity towards ethanol electrooxidation in alkaline solution by Li et. al., [72]. In another research work the use of some nanoporous metallic structures have been reported by electrochemical deposition using hard and soft templates because of the presence of large specific surface area, pore volume, faster as well as easy mass transport of reactants and provide high accessibility to catalytically active metallic sites and thus, provide a new pathways to control the nanoporous architechures for various applications including sensors and energy storage [73].

It is observed that Platinum alloyed with some other selected metals serve both the purpose of removing $\mathrm{CO}$ adsorbed from the active surface, promote the formation of more $\mathrm{OH}$ species and enhance methanol electrooxidation at lower potentials and temperatures under commonly used acidic conditions. In the development of DMFCs and other fuel cell applications, both methanol electro-oxidation at the anode electrode as well as the reduction of $\mathrm{O}_{2}$ at the cathode electrode (ORR) are very important for their commercialization. Further, because of the adsorption of oxygen on the cathode, the reaction kinetics is very poor for ORR and therefore, a higher loading of platinum is required at the cathode which inturn affects the overall cost of the fuel cell. Li et. al., reviewed Pt-based electrocatalysts with highly open nanoarchitechures for improving ORR for better electrochemical behavior of the fuel cell mainly because of the availability of more active platinum sites and easy mass transport [74]. All these catalysts exhibit much higher electrochemical activity mainly because of their electrochemical surface area, e.g., Pd-Pt nanodendrite has ECSA value of $57.1 \mathrm{~m}^{2} / \mathrm{g}$ and the mass activity are 2.5 to 5 times higher to that observed for $\mathrm{Pt} / \mathrm{C}$ and $\mathrm{PtB}$ (platinum 


\section{Advanced Materials Letters www.vbripress.com/aml}

black). Similar enhancements of electrochemical activities were also observed for Pt-based ultrathin monometallic $\mathrm{Pt}$ nanowires, subnanometer $\mathrm{PtNi}, \mathrm{PtCo}, \mathrm{PtNiCo}$ nanowires and Pt-based nanoframes etc.

Under the category PtCo alloys having with different compositions of platinum and cobalt and anchored on various support materials (rGO, CNTs, N-rGO, g- $\mathrm{C}_{3} \mathrm{~N}_{4}$ etc), rGO has been found to perform remarkable enhancement in the electrocatalytic activity for MOR $[13,15,19,26,51,63-68,75-79]$. Out of the different compositions of $\mathrm{Pt}$ and Co in PtCo alloy, a Pt: Co molar ratio of 1:9 was found to exhibit higher electrochemical behavior towards MOR in acidic condition in comparison to $\mathrm{Pt} / \mathrm{C}[19]$. The present review paper describes some of our work carried out in our laboratory on the electrooxidation of methanol in acidic medium where $\mathrm{Pt}$ and $\mathrm{Pt}$ based alloy nanoparticles are mainly supported on rGO, $\mathrm{N}$-doped reduced graphene oxide (N-rGO) and a hybrid of rGO and CNTs. The performance of the as-synthesized electrocatalysts on different support materials is compared with Pt/C (Alfa Aesar).

\section{Experimental \& methods}

\section{Materials required}

The reagen and chemicals used in the present work were of high purity (> 98\%) and obtained from either Merck or Sigma-Aldrich. Chloroplatinic acid hexahydrate $\left(\mathrm{H}_{2} \mathrm{PtCl}_{6}\right.$. $6 \mathrm{H}_{2} \mathrm{O}$, ammonium hydroxide solution $\left(\sim 25 \% \mathrm{NH}_{3}, \mathrm{AR}\right)$, hydrazine hydrate solution $(50-60 \%$ in water, $99.99 \%$ purity), sulfuric acid (> 98\%), Hydrochloric acid (35$37 \%$ ), toluene (> 98\%), sodium nitrate (>98\%), $\mathrm{KMnO}_{4}$ (> 98\%), hydrogen peroxide solution (30\% in water), sodium hydroxide (>98\%), Nafion solution 117 and ferrocene (98\%) were all obtained from Sigma-Aldrich. Methanol was supplied by Merck. Graphite having 99.999\% purity was purchased from USA.

Synthesis of graphene oxide, reduced graphene oxide, $N$-doped reduced graphene oxide, acid functionalized multiwalled carbon nanotubes (fCNTs and a hybrid of rGO and CNTs

Graphene oxide (GO) was prepared by a chemical process to as reported by a modified Hummer's method [80-84]. It has been found that using Hummer's method few unoxidized peaks of graphite as also observed in the XRD pattern. In order to avoid this modified Hummer's method is generally used for the preparation of high-quality GO. In this method pre-oxidized graphite was used instead of graphite powder. This pre-oxidized graphite was obtained from natural flake like oxidized in presence of $\mathrm{K}_{2} \mathrm{~S}_{2} \mathrm{O}_{8}$ and $\mathrm{P}_{2} \mathrm{O}_{5}$ and the $\mathrm{pH}$ value of the solution is maintained continuously during the reaction [82]. In the present work, an almost same procedure was used in the preparation of GO powder. In summary, $0.5 \mathrm{~g}$ of pre-oxidized graphite powder as prepared above [82] was added to $23 \mathrm{~mL}$ $\mathrm{H}_{2} \mathrm{SO}_{4}$. To this solution was added $0.5 \mathrm{~g} \mathrm{NaNO}_{3}$ followed by the addition of $1.5 \mathrm{~g}$ of $\mathrm{KMnO}_{4}$ under vigorous stirring at $0^{\circ} \mathrm{C}$ in order to prevent overheating and explosion. The solution was then kept at $30-40{ }^{\circ} \mathrm{C}$ for $12 \mathrm{~h}$ under continuous stirring. After that the resulting solution was diluted by adding $500 \mathrm{~mL}$ DI water. The oxidation level of graphene oxide was improved by treating the resulting mixture with $30 \% \mathrm{H}_{2} \mathrm{O}_{2}(5 \mathrm{~mL})$ and to remove the $\mathrm{Mn}$ salts. GO was obtained as a yellow-brown after centrifugating the solution at $15000 \mathrm{rpm}$ for 10 minutes following by washing with dilute $\mathrm{HCl}$ and water. From a detailed experimentation it was observed that if the centrifugation was carried out at lower rpm $(<15000 \mathrm{rpm})$ the product was always contaminated with GO and unoxidized graphite (as evidenced by XRD, not shown here). GO powder was finally dried by heating it at $60^{\circ} \mathrm{C}$ under a vacuum oven for overnight. $\mathrm{rGO}$ was then prepared from GO by chemical reduction employing a number of reducing agents including aqueous solution sodium borohydride [85-88], sodium-ammonia solution as the reducing agent [89], L-ascorbic acid, a mixture of citric acid and hydrazine hydrate in alkaline medium [90] and refluxing in ethylene glycol and others $[\mathbf{9 , 2 5 , 9 1 ]}$. As hydrazine hydrate is a toxic reducing agent it is used with ammonia solution or with citric acid as mentioned above. A modified hydrothermal was used to prepare $\mathrm{rGO}$ at $140{ }^{\circ} \mathrm{C}$ for $6 \mathrm{~h}$ under constant stirring at a $\mathrm{pH}$ value of 11 adjusted by $\mathrm{NaOH}[\mathbf{9 2}]$.

Multiwalled carbon nanotubes (CNTs) used for the preparation of $\mathrm{rGO} / \mathrm{CNT}$ s hybrid were synthesized in our laboratory by the thermal chemical vapor decomposition of toluene at $750^{\circ} \mathrm{C}$ in the presence of ferrocene catalyst [93]. These CNTs were functionalized by refluxing in a mixture of nitrice acid and sulphuric acid taken in a volume ratio of $1: 1$ at about $100{ }^{\circ} \mathrm{C}$ for $4 \mathrm{~h}$. $\mathrm{N}$-doped rGO was prepared by heating a mixture of graphene oxide (GO) and melamine powder at $900{ }^{\circ} \mathrm{C}$ in presence of $\mathrm{Ar}$ for 30 minutes [94]. For this purpose about $50 \mathrm{mg}$ of $\mathrm{GO}$ powder was initially dispersed in water followed by adding $0.250 \mathrm{~g}$ of melamine powder and again sonicated. The solution was dried in an oven at around $80{ }^{\circ} \mathrm{C}$ to obtain solid GO and melamine. The mixture was crushed to fine powder and finally heated at $900{ }^{\circ} \mathrm{C}$ in $\mathrm{Ar}$ for 30 minutes to obtain $\mathrm{N}-\mathrm{rGO}$ powder. The $\mathrm{N}$ content in this powder was estimated to be around $8 \%$. The hybrid of rGO and CNTs was prepared in accordance to the method as reported by Woo et. al., [95]. Briefly, a mixture GO powder and acid functionalized CNTs in a $2: 1 \mathrm{w} / \mathrm{w}$ was first ultrasonicated and then treated with a 1:1 mixture of hydrazine hydrate and ammonium hydroxide solution in a water bath at around $95{ }^{\circ} \mathrm{C}$ for about $1 \mathrm{~h}$. On completion of the reaction, the $\mathrm{rGO}$ and fCNTs powders were obtained by filtration and drying in oven.

\section{Preparation of rGO supported PtCo, PtCu/N-doped rGO and $\mathrm{Pt} / \mathrm{rGO}$-fCNTs electrocatalysts}

The various electrocatalysts used for MOR under acidic midium are rGO supported $\mathrm{PtCo}, \mathrm{PtCu} / \mathrm{N}$-doped $\mathrm{rGO}$ and $\mathrm{Pt} / \mathrm{rGO}-\mathrm{fCNTs}$ and were prepared using chemical reduction. Various compositions of $\mathrm{PtCo}$ and $\mathrm{PtCu}$ alloys supported on rGO and $\mathrm{N}$-rGO were used for MOR. 


\section{Advanced Materials Letters www.vbripress.com/aml}

However, only Pt supported on a hybrid of rGO and fCNTs was used in the present work. The electrocatalysts consisting of rGO $\mathrm{Pt}$ and $\mathrm{Co}$ in a pre-calculated molar ratios in chloroplatinic acid hexahydrate $\left(\mathrm{H}_{2} \mathrm{PtCl}_{6} \cdot 6 \mathrm{H}_{2} \mathrm{O}\right)$ and cobalt chloride hexahydrate $\left(\mathrm{CoCl}_{2} \cdot 6 \mathrm{H}_{2} \mathrm{O}\right)$ were mixed thoroughly in ethylene glycol-water solution using ultrasonication for $2 \mathrm{~h}$ to ensure their homogeneous mixing and then refluxed at $120{ }^{\circ} \mathrm{C}$ for $5 \mathrm{~h}$ with continuous stirring. The $\mathrm{pH}$ of the solution was maintained constant at 9 throughout the reaction. The resulting product consisting of rGO supported PtCo electrocatalyst was separated by filtration, washing with DI water and then vacuum drying under normal P-T conditions $[\mathbf{6 , 1 9 , 2 4 ]}$. In this way various $\mathrm{PtCo} / \mathrm{rGO}$ electrocatalysts with Pt: Co of 1:1, 1:5, 1:9 \& 1:11 were synthesized keeping the metal: support ratio of 20:80 by weight in all the catalysts. Pure Pt supported on rGO was also prepared similarly for comparision of electrochemical behavior in addition to commercially available $\mathrm{Pt} / \mathrm{C}$ containing $20 \mathrm{wt} \% \mathrm{Pt}$.

From the various compositions of $\mathrm{Pt}$ and $\mathrm{Cu}$ in $\mathrm{PtCu}$ alloy catalysts supported on N-rGO, a 1:2 of platinum and copper was found to exhibit higher MOR as compared to $\mathrm{PtCu} / \mathrm{rGO}[\mathbf{9 6 , 9 7}], \mathrm{PtCu} / \mathrm{C}[\mathbf{9 8 , 9 9}]$ and $\mathrm{C}$ supported $\mathrm{Pt}$ and its alloys [65]. Therefore, in the present work much attention has been paid to study the MOR using PtCu alloy in a 1:2 molar ratio supported on $\mathrm{N}$-rGO. This electrocatalyst was prepared first exfoliating $\mathrm{N}-\mathrm{rGO}(50 \mathrm{mg})$ in $20 \mathrm{ml}$ ethylene glycol for $1 \mathrm{~h}$. To this solution a mixture of $\mathrm{H}_{2} \mathrm{PtCl}_{6}$ and $\mathrm{CuCl}_{2} \cdot 6 \mathrm{H}_{2} \mathrm{O}(0.03 \mathrm{M}$ each, 1:2 molar ratio) was added. The solution was sonicated for $2 \mathrm{~h}$ under constant stirring. The chemical reaction was carried out at $180{ }^{\circ} \mathrm{C}$ for $3 \mathrm{~h}$. Finally a electro-catalyst comprising of $\mathrm{PtCu}(1: 2) / \mathrm{N}-\mathrm{rGO})$ was obtained by washing with ethanol, filtration followed by freeze drying. Other catalysts were also prepared in a similar manner for comparison of various results.

Pt nanoparticles supported on a hybrid of fCNTs and rGO was prepared by in-situ chemical reduction of exfoliated GO and chloroplatinic acid hexahydrate in the presence of acid functionalized multiwalled CNTs using a 1:1 mixture of hydrazine hydrate and ammonium hydroxide solution [45]. In a typical experiment a rGO-CNTs composite $(2: 1$, w/w) was synthesized by exfoliating $200 \mathrm{mg}$ of graphene oxide powder in $100 \mathrm{ml}$ DI water by ultrasonication for $1 \mathrm{~h}$ and then $100 \mathrm{mg}$ of acid functionalized CNTs was added to the above solution under continuous stirring for another $1 \mathrm{~h}$. In another beaker $60 \mathrm{mg}$ of chloroplatinic acid hexahydrate was dissolved in $10 \mathrm{ml}$ of water and neutralized by adding $1 \mathrm{M} \mathrm{NaOH}$ in order to achieve a $\mathrm{pH}$ of 11.7. This solution was then added very slowly to the flask containing exfoliated GO and CNTs. The reduction was done by the addition of $1: 1$ mixture of hydrazine hydrate and ammonium hydroxide $\left(10 \mathrm{ml}\right.$ each) at $95{ }^{\circ} \mathrm{C}$ for $1 \mathrm{~h}$ in an oil bath. After the completion of reaction, the product consisting of $\mathrm{Pt}$ nanoparticles deposited on $\mathrm{rGO} / \mathrm{CNTs}$ hybrid was obtained by filtration and drying. Pt/rGO was also prepared in a similar method.

\section{Physichochemical characterization}

Powder X-ray diffraction technique was used to study the crystalline structure identification of various samples (GO, rGO and various Pt based electrocatalyst) sprepared in this work using $\mathrm{CuK} \alpha$ radiation $(\lambda=0.15405 \mathrm{~nm})$ where the $2 \theta$ was varied 5 and $80^{\circ}$ and a scan rate of $2 \%$ min. The particle size of $\mathrm{Pt}$ in all the electrocatalysts synthesized in this work was calculated from the (111) peak using the Scherrer's formula. Surface morphology of $\mathrm{Pt}, \mathrm{PtCo}$ and $\mathrm{PtCu}$ nanoparticles and their dispersion on $\mathrm{rGO}$ and $\mathrm{rGO} / \mathrm{CNTs}$ hybrid material was studied using a scanning electron microscope and a transmission electron microscope. GO and few electrocatalysts synthesized were also characterized using Raman spectroscopy with an excitation laser source of $514 \mathrm{~nm}$ wavelength and recording the spectrua were from $1000 \mathrm{~cm}^{-1}$ to $3000 \mathrm{~cm}^{-1}$. FTIR was used to analysis the various functional groups attached on to the surface of GO from $500 \mathrm{~cm}^{-1}$ to $4000 \mathrm{~cm}^{-1}$. The platinum loading in all the electrocatalysts was calculated to be $89 \mu \mathrm{g}$ using AAS. The details of different characterization instruments and their model used are described in detail in our earlier paper [19].

\section{Electrochemical behavior of Pt based electrocatalysts}

The electrochemical behavior of different $\mathrm{Pt}$ based electrocatalysts supported on various carbon materials and prepared in the present work were measured in terms of their catalytic activity, durability and long-term stability using cyclic voltammetry and resistance to charge transfer $\left(\mathrm{R}_{\mathrm{CT}}\right)$ using Electrochemical Impedence Spectroscopy (EIS). It has been found that the electrochemical activity of all the electrocatalysts depend strongly on the electrochemical surface area of platinum in the catalysts, average particle size, their dispersion of these nanoparticles on the support material, the interaction of the support with the metallic phase and the number of available active Pt sites. The catalytic behaviour of Pt and different electrocatalysts on various carbon support materials were measured using cyclic voltammetry using a three electrodes electrochemical work station consisting of a working electrode prepared from the electrocatalyst slurry by dropcasting about $2.5 \mathrm{mg}$ on a glassy carbon (GC) [3 $\mathrm{mm}$ diameter, $0.07 \mathrm{~cm}^{2}$ area, a reference electrode and a counter electrode made from Pt mesh. The details for the preparation of working electode are described elsewhere [19].

The electrochemical surface area (ECSA) of platinum in the as-synthesized electrocatalysts was estimated from the $\mathrm{CV}$ curves of the $\mathrm{H}_{2}$ adsorption in a $\mathrm{N}_{2}$ saturated $1 \mathrm{M} \mathrm{H}_{2} \mathrm{SO}_{4}$ solution. The ESCA of $\mathrm{Pt}$ in a particular electrocatalyst provides the information about the electrochemical behavior and the number of $\mathrm{Pt}$ sites available for MOR and is also very useful to compare the electrochemical activities of different electrocatalysts supported on various carbon supports [24]. 


\section{Advanced Materials Letters www.vbripress.com/aml}

The ECSA of Pt in the catalysts synthesized in the present work were calculated from the $\mathrm{CVs}$ for $\mathrm{rGO}$ supported PtCo alloy, PtCu/N-rGO and $\mathrm{Pt} / \mathrm{rGO}-\mathrm{CNTs}$ catalysts were recorded in acidic medium containing $1 \mathrm{M}$ sulfuric acid. The ECSA was calculated from the total integrated area for $\mathrm{H}+$ adsorption in the $\mathrm{CV}$ curves using the following equation [13]:

$$
\begin{gathered}
E C S A\left(m^{2} / g \text { of } P t\right)=\ldots Q_{H}- \\
P t \times 0.21
\end{gathered}
$$

where $\mathrm{Pt}$ is in $\mathrm{g} / \mathrm{cm}^{2}, Q_{H}$ is the charge for $\mathrm{H}_{2}$ desorption $\left(\mathrm{mC} / \mathrm{cm}^{2}\right)$, and 0.21 is charge required to oxidize a monolayer of $\mathrm{H}_{2}$ on $\mathrm{Pt}\left(\mathrm{mC} / \mathrm{cm}^{2}\right)$.

Electrochemical activity of different electrocatalysts prepared in the present work towards MOR is measured in acidic medium. The long term stability of different electrocatalysts was analyzed from the chronoamperometric curves performed at $0.6 \mathrm{~V}$ in $2 \mathrm{M}$ methanol and $1 \mathrm{M}$ sulfuric acid from 500 to 1000 s at normal conditions.

\section{Testing of a direct methanol fuel cell}

The electrochemical performance of different electrocatalysts on various carbon supports towards MOR was tested in a single cell using the conventional method employing a membrane electrode assembly as reported [100]. The anodes were prepared from rGO supported pure $\mathrm{Pt}$ as well as PtCo alloy nanoparticles having Pt:Co of 1:1, 1:5, 1:9 and 1:11 respectively with a loading of 3 $\mathrm{mg} / \mathrm{cm}^{2}$. The cathode was a Pt/C having $40 \mathrm{wt} \%$ of Pt. The experimental details for this single test in a DMFC are described elsewhere [19]. However, the MEA was prepared by sandwiching the anode and the cathode using Nafion 117 membrane. Methanol concentration of $2 \mathrm{M}$ with a pressure of 1 bar and flow rate of $1 \mathrm{~mL} / \mathrm{min}$ was used at the anode and the oxygen flow rate of $200 \mathrm{sccm}$ with a flow rate of 1.5 bar was used at the cathode.

\section{Results and discussion}

\section{Methanol electro-oxidation using rGO supported PtCo alloy electrocatalysts}

A schematic diagram showing the synthesis of PtCo nanoparticles with different Pt:Co ratio and supported on rGO is represented by Fig. 2.

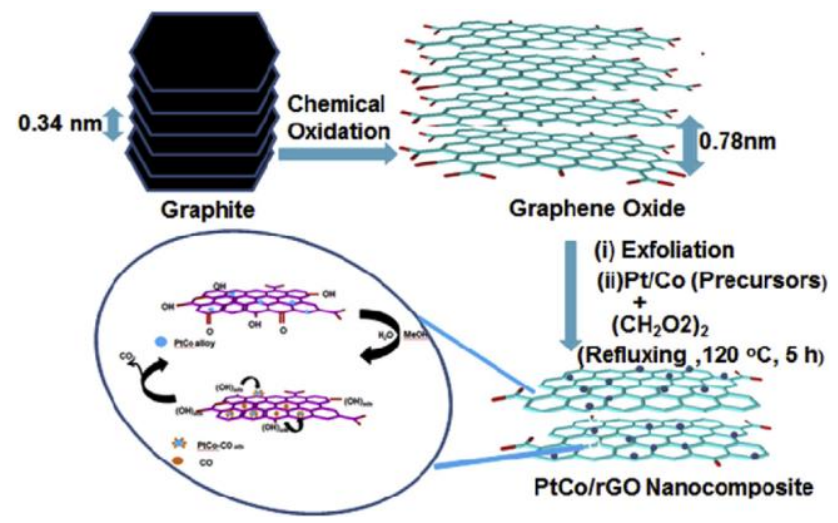

Fig. 2. Schematic for the preparation of $\mathrm{PtCo} / \mathrm{rGO}$ nanocomposite [19].
From this schematic diagram it is noticed that the "d" is increased from 0.34 to $0.78 \mathrm{~nm}$ during the transformation of graphite to graphene oxide which is mainly because of the presence of various oxygencontaining functional groups on its surface and are useful in the enhancement of MOR [101].

\section{Characterization of electrocatalysts using X-ray diffraction}

Fig. 3 shows the XRD spectra of rGO supported Pt and rGO supported PtCo alloy electrocatalyst using $\mathrm{Cu}-\mathrm{K} \alpha$ radiation $(\lambda=0.1548 \mathrm{~nm})$. The XRD peaks for GO (100) and rGO (002) are normally observed at a $2 \theta$ value of 11.26 , and $24.06^{\circ}$ respectively.

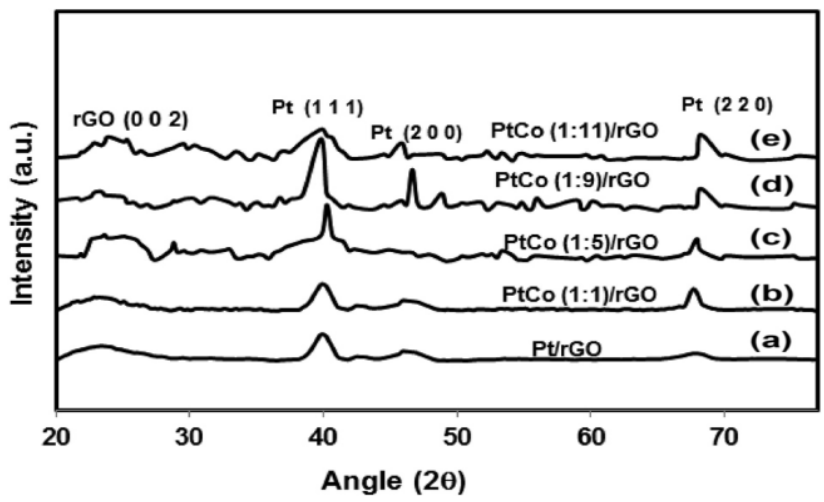

Fig. 3. XRD spectra of (a) $\mathrm{Pt} / \mathrm{rGO}$, (b-e) $\mathrm{PtCo} / \mathrm{rGO}$ electrocatalyst with Pt:Co ratio of 1:1, 1:5, 1:9 and 1:11 [19]

From the XRD spectra of Pt/rGO (Fig. 3a) it is seen that almost all the XRD peaks of fcc structure of $\mathrm{Pt}$ at $2 \theta=$ 39.54, 45.90 and $67.9^{\circ}$ are observed. However, a broad peak at $23.44^{\circ}$ is also observed in this spectra which is mainly due to (002) plane of ordered carbon from reduced graphene oxide. From the XRD spectra observed from PtCo nanoparticles supported on rGO with different Pt:Co ratio, it is seen that the general characteristics is more or less similar to that of $\mathrm{Pt} / \mathrm{rGO}$ except that the XRD peak due to Pt (111) reflection is shifted to slightly higher $2 \theta$ values indicating the incorporation of cobalt in platinum lattice as a result of lattice contraction and the formation of $\mathrm{PtCo}$ alloy in $\mathrm{PtCo} / \mathrm{rGO}$ electrocatalyst. Further the absence of any other peak in the XRD peak suggests the formation of pure PtCo alloy. The Scherer's equation was used to calculate the average crystallite size from the (111) plane of Pt and the results are shown in Table 1 alongwith ' $\mathrm{d}$ ' spacing and lattice parameter for $\mathrm{Pt} / \mathrm{rGO}$ and $\mathrm{PtCo} / \mathrm{rGO}$ electrocatalysts.

$$
\mathrm{D}=\frac{0.89 \kappa}{\beta \operatorname{Cos} \theta}
$$

The particle size of $\mathrm{Pt} / \mathrm{rGO}$ and $\mathrm{PtCo} / \mathrm{rGO}$ electrocatalysts with different Pt:Co ratio was found to be $\sim 5 \mathrm{~nm}$ and $\sim 2 \mathrm{~nm}$. Also, it has been found that with the increase in cobalt concentration in PtCo alloy, there is a decrease in lattice parameter because of the reduction in interatomic spacing between $\mathrm{Pt}$ atoms which inturn enhances the electrochemical performance of rGO supported PtCo alloy electrocatalysts towards MOR [102]. 


\section{Advanced Materials Letters www.vbripress.com/aml}

Table 1. ' $\mathrm{d}$ ' spacing, lattice parameter and particle size of $\mathrm{Pt} / \mathrm{rGO}$ and $\mathrm{PtCo} / \mathrm{rGO}$ electrocatalysts with different Pt:Co ratio in the PtCo alloy.

\begin{tabular}{|c|c|c|c|}
\hline Electrocatalyst & 'd' ${ }_{(111)}$ & $\left(\mathbf{a} / \mathbf{A}^{\mathbf{0}}\right)$ & D $(\mathbf{n m})$ \\
\hline $\mathrm{Pt} / \mathrm{rGO}$ & 2.32 & 4.01 & 4.58 \\
\hline $\operatorname{PtCo}(1: 1) / \mathrm{rGO}$ & 2.28 & 3.95 & 3.35 \\
\hline $\operatorname{PtCo}(1: 5) / \mathrm{rGO}$ & 2.21 & 3.82 & 2.74 \\
\hline $\mathrm{PtCo}(1: 9) / \mathrm{rGO}$ & 2.19 & 3.70 & 2.12 \\
\hline
\end{tabular}

\section{Morphology of the as-synthesized electrocatalysts}

The morphology and structure of the as-synthesized electrocatalysts with different composition of $\mathrm{Pt}$ and $\mathrm{Co}$ in the $\mathrm{PtCo} / \mathrm{rGO}$ catalyst was analyzed using SEM and TEM and these results are represented in Fig. 4.

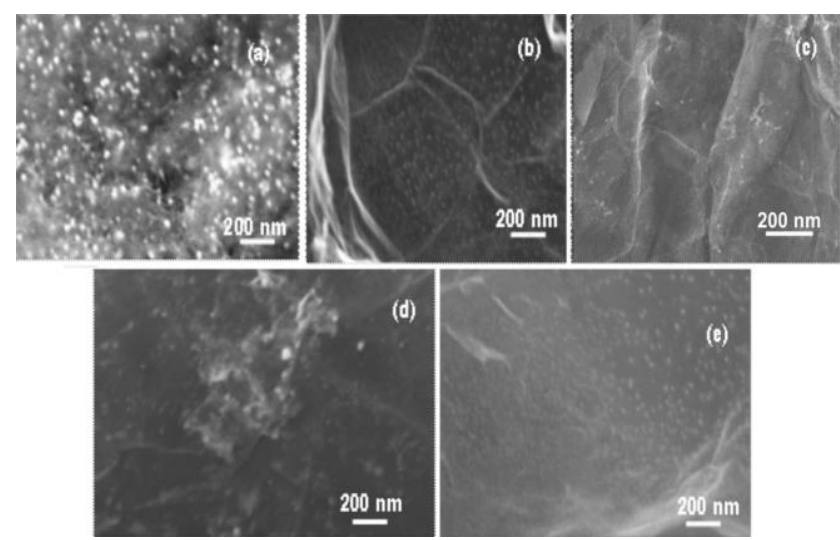

Fig. 4. SEM images of (a) $\mathrm{Pt} / \mathrm{rGO}$ (b-e) $\mathrm{PtCo} / \mathrm{rGO}$ electrocatalysts with Pt:Co ratio of $1: 1,1: 5,1: 9$ and $1: 11[\mathbf{1 9}]$.

Fig. 4 (a-e) represent the SEM images of $\mathrm{Pt} / \mathrm{rGO}$ other electrocatalysts with different Pt:Co molar ratio supported on rGO. From these images is seen the $\mathrm{Pt}$ nanoparticles are almost agglomerated in $\mathrm{Pt} / \mathrm{rGO}$ catalyst (Fig. 4a), but more uniformly dispersed on rGO nanosheets in case of $\mathrm{PtCo} / \mathrm{rGO}$ catalysts and the best homogeneous dispersion is observed with $\mathrm{PtCo} / \mathrm{rGO}$ electrocatalyst with a Pt:Co ratio of 1:9 (Fig. 4e). The morphology and structural analysis of $\mathrm{Pt} / \mathrm{rGO}$ and $\mathrm{PtCo} / \mathrm{rGO}$ catalyst with a Pt:Co molar ratio of $1: 9$ is also done using TEM with HRTEM and are represented in Fig. 5(a-f).

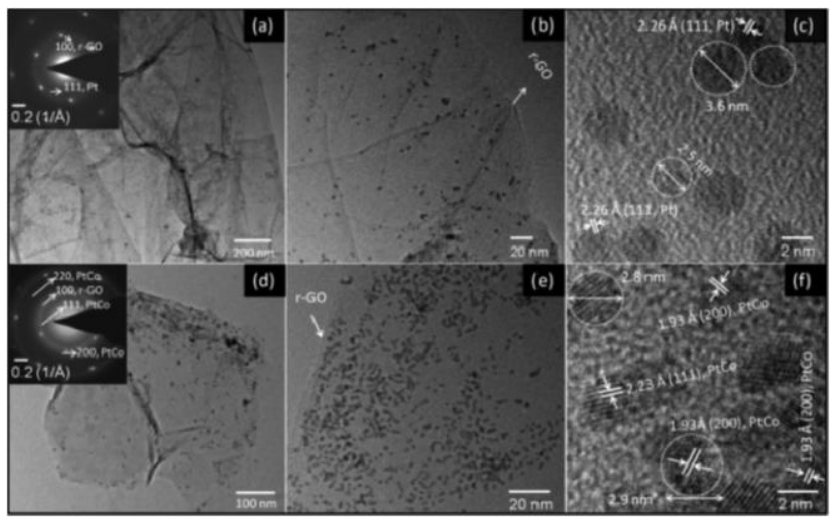

Fig. 5. TEM images of $\mathrm{Pt} / \mathrm{rGO}$ and $\mathrm{PtCo} / \mathrm{rGO}$ electrocatalyst Fig. (a, b) and (d-e) are the TEM images of $\mathrm{Pt} / \mathrm{rGO}$ and $\mathrm{PtCo} / \mathrm{rGO}$ electrocatalyst. Fig (c) and (f) are HRTEM images of Pt/rGO and PtCo/rGO. Left top inset Fig. (a) and (d) are the SAED pattern of Pt/rGO and PtCo /rGO. In all the $\mathrm{PtCo} / \mathrm{rGO}$ electrocatalyst the Pt:Co ratio was 1:9 [19].
From the HRTEM images represented in Fig. 5(c \& f) the crystallite size of the $\mathrm{Pt}$ and $\mathrm{PtCo}$ nanoparticles was found to be around 5 and $2 \mathrm{~nm}$ which are in consistent with the XRD results earlier obtained. The smaller particle size of PtCo in $\mathrm{PtCo} / \mathrm{rGO}$ electrocatalysts with a Pt:Co of 1:9 reflects its higher electrochemical activity in comparison to $\mathrm{Pt} / \mathrm{rGO}$.

It has been observed that graphene has a sixfold symmetry diffraction due to (100) plane in a SAED pattern Pt exhibits multiple crystalline reflections of (111) and (220) planes. The same characteristics of rGO and Pt in $\mathrm{Pt} / \mathrm{rGO}$ and $\mathrm{PtCo} / \mathrm{rGO}$ electrocatalyst having a $\mathrm{Pt}: \mathrm{Co}$ ratio of 1:9 are observed in the inset of Fig. 5(a \& d). HRTEM image (Fig. 5f) of $\mathrm{PtCo} / \mathrm{rGO}$ catalyst with a Pt:Co ratio of 1:9 shows the 'd' spacing's of 2.23 and 2.19 $\mathrm{A}^{\mathrm{o}}$ corresponding to (111) and (220) planes of PtCo. The decrease in 'd'values of PtCo alloy in comparison to that of pure Pt (111) is explained by the substtution of cobalt for Pt thus confirming the formation of PtCo alloy and that these results are in consistent with the XRD results.

\section{Electrochemical performance}

\section{Electrochemical surface area (ECSA)}

As ECSA of Pt in a particular electrocatalyst is very important as it provides very important information on the electrochemical activity of a particular catalyst for MOR. Using eq. (1) the ECSA of $\mathrm{Pt}$ in the as-synthesized electrocatalysts was calculated to be much higher $\left(320.386 \mathrm{~m}^{2} / \mathrm{g}\right)$ for PtCo nanoparticles supported on rGO with a Pt:Co ratio of $1: 9$ as compared to other combinations of $\mathrm{Pt}: \mathrm{Co}$ in $\mathrm{rGO}$ supported $\mathrm{PtCo}$ nanoparticles having a ratio of $1: 1\left(17.86 \mathrm{~m}^{2} / \mathrm{g}\right), 1: 5$ $\left(158.876 \mathrm{~m}^{2} / \mathrm{g}\right), 1: 11\left(197.279 \mathrm{~m}^{2} / \mathrm{g}\right)$ and $\left.9.436 \mathrm{~m}^{2 /} \mathrm{g}\right)$ for $\mathrm{Pt}$ nanoparticles supported on rGO respectively. It is noticed that ECSA value for the electrocatalyst having a 1:9 Pt: Co ratio is much higher to those observed for $\mathrm{Pt} / \mathrm{rGO}$ and $\sim 5-8$ times higher than $\mathrm{Pt} / \mathrm{C}$ catalyst $\left(38.87-57.5 \mathrm{~m}^{2} / \mathrm{g}\right)[\mathbf{1 5}, \mathbf{2 7}, \mathbf{5 1}]$, thereby revealing that the Pt:Co molar ratio of 1:9 in the $\mathrm{PtCo} / \mathrm{rGO}$ electrocatalyst is much better for the fabrication of anode in comparison with other compositions of $\mathrm{Pt}$ and $\mathrm{Co}$ in the PtCo alloy. The enhancement in ECSA for 1:9 Pt:Co electrocatalyst supported on mainly due to the homogeneous distribution of $2 \mathrm{~nm}$ PtCo nanoparticles on reduced graphene oxide and that the addition of cobalt metal to Pt also promote the MOR as it minimized the adsorption of $\mathrm{CO}$ on $\mathrm{Pt}$ active sites because of its oxophilic nature [28].

\section{Electro-oxidation of methanol}

The electrochemical activity of the as synthesized anode electrocatalysts with different ratio of $\mathrm{Pt}$ and $\mathrm{Co}$ in $\mathrm{PtCo}$ alloy nanoparticles anchored on reduced graphene oxide towards MOR was studied employing $\mathrm{CV}$ at room temperature in acidic medium in a 3-electrodes electrochemical work station in acidic medium using sulfuric acid as the electrolyte with a scanning rate of 20 $\mathrm{mV} / \mathrm{s}$ in $0-1.0$ Volt vs $\mathrm{Ag} / \mathrm{AgCl}$. The $\mathrm{CV}$ curves of this 


\section{Advanced Materials Letters www.vbripress.com/aml}

measurement are represented in Fig. 6. In this figure, MOR in the forward scan is shown by the anodic peak current density $\left(\mathrm{I}_{\mathrm{F}}\right)$ at about $0.7 \mathrm{~V}$, and in the reverse direction the cathodic peak current density $\left(\mathrm{I}_{\mathrm{B}}\right)$ is mainly attributed to the removal of poisoneous carbon monoxide and other $\mathrm{C}$-intermediates formed during the forward scan [78].

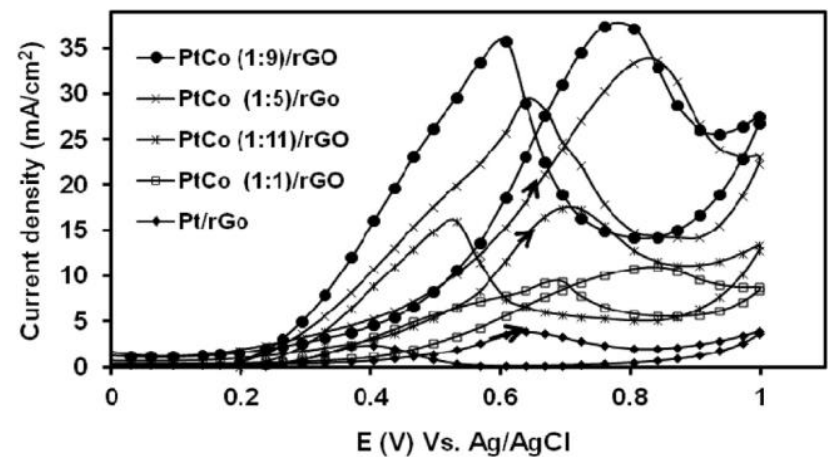

Fig. 6. $\mathrm{CV}$ curves obtained during $\mathrm{MOR}$ for $\mathrm{Pt} / \mathrm{rGO}$ and $\mathrm{PtCo} / \mathrm{rGO}$ electrocatalysts having a different molar ratio of $\mathrm{Pt}$ and $\mathrm{Co}$ in $\mathrm{PtCo}$ alloy in $1 \mathrm{M} \mathrm{H}_{2} \mathrm{SO}_{4}$ and $2 \mathrm{M} \mathrm{CH}_{3} \mathrm{OH}$ [19].

From Fig. 6 it is seen that maximum anodic peak density of $3.85,11.01,33.90,38.02$ and $17.26 \mathrm{~mA} / \mathrm{cm}^{2}$ was exhibited by $\mathrm{Pt} / \mathrm{rGO}$ and $\mathrm{PtCo} / \mathrm{rGO}$ anode electrocatalysts with a $\mathrm{Pt}: \mathrm{Co}$ ratio of $1: 1,1: 5,1: 9$ and 1:11 respectively in the forward scan. A highest value of anodic current density in case of assynthesized anode electrocatalyst with a Pt:Co ratio of 1:9 $\left(38.02 \mathrm{~mA} / \mathrm{cm}^{2}\right)$ indicates that its electrochemical activity is higher by 23 times in comparison to $\mathrm{Pt} / \mathrm{C}$ anode catalyst $\left(1.68 \mathrm{~mA} / \mathrm{cm}^{2}\right)$ and nearly 10 times higher than that exhibited by $\mathrm{Pt} / \mathrm{rGO}$ anode electrocatalyst [77]. The lower values of forward anodic current density means the accumulation of more $\mathrm{CO}$ or carbonaceous intermediates on Pt surface, leading to decrease the efficiency of the catalyst. Thus the catalytic activity of $\mathrm{PtCo} / \mathrm{rGO}$ catalyst with a Pt:Co molar ratio of $1: 9$ is highest than those exhibited by other catalysts studied in this work.

The higher electrochemical activity this electrocatalyst is mainly due to its higher ECSA, more homogeneous dispersion of small size PtCo alloy nanoparticles on rGO, oxophyllic nature of cobalt atom in the PtCO alloy which promotes the activation of water, thus producing more $\mathrm{OH}$ species which are helpful in minimizing the adsorption of $\mathrm{CO}$ and other carbon intermediates on the Pt surfaces in accordance with the bifunctional mechanism [28]. From Fig. 6 it is seen that this effect of improving the electrochemical activity towards MOR was more pronounced in case of $\mathrm{PtCo} / \mathrm{rGO}$ electrocatalyst with a $\mathrm{Pt}: \mathrm{Co}$ of $1: 9$ as compared to other compositions of $\mathrm{Pt}$ and $\mathrm{Co}$ in the $\mathrm{PtCo} / \mathrm{rGO}$ catalysts. Therefore, because of the higher electrochemical activity of PtCo alloy nanoparticles supported on a various materials such as carbon nanotubes, graphene, rGO etc it has been studied widely towards MOR both in acidic as well as in alkaline medium. The ratio of $\mathrm{Pt}$ and $\mathrm{Co}$ in the PtCo alloy was varied in all these studies. Huang et. al.
[13] reported methanol electro-oxidation using PtCo alloy 1:1) nanoparticles supported on rGO as well as on CNTs and obtained a anodic current densities of 35.8 and 19.6 $\mathrm{mA} / \mathrm{cm}^{2}$ respectively in acidic medium. Kepeniene et. al. [15] observed highest anodic current density of about 80 $\mathrm{mA} / \mathrm{cm}^{2}$ in case of $\mathrm{PtCo}(1: 7) /$ graphene electrocatalyst studied in alkaline medium. Very recently Hakan et. al. [66] reported that monodisperse $\mathrm{PtCo} / \mathrm{GO}$ electrocatalysts with varying $\mathrm{Pt}$ :Co ratios exhibits activity and stability towards electro-oxidation reaction. A maximum anodic current density of $22 \mathrm{~mA} / \mathrm{cm}^{2}$ was exhibited by $\mathrm{Pt}_{75} \mathrm{Co}_{25} @ \mathrm{GO}$ electrocatalyst. The LSV results (Fig. 7) shows the lowest onset potential exhibited by $\mathrm{PtCo} / \mathrm{rGO}$ catalyst with a Pt:Co molar ratio of 1:9 as compared to $\mathrm{Pt} / \mathrm{rGO}$ catalyst. The lower onset potential means that it is much easier to break the $\mathrm{C}-\mathrm{H}$ bond in methanol and thus more advantageneous for faser MOR kinetics [78].

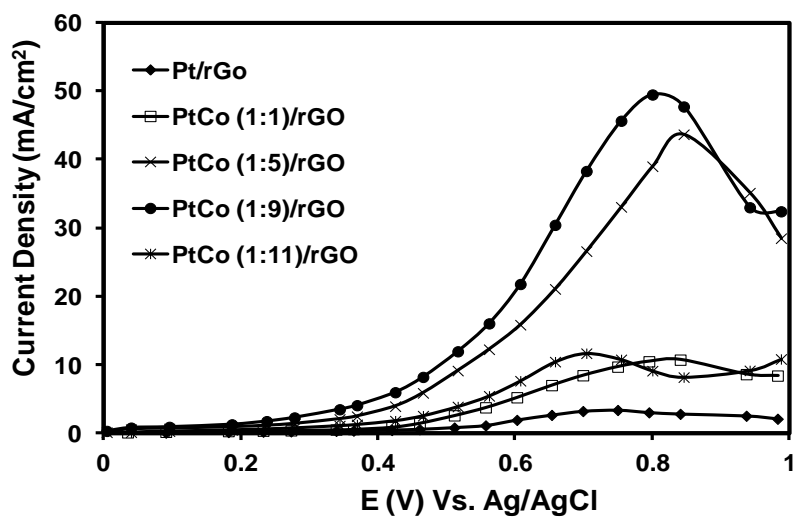

Fig. 7. LSV of (a) $\mathrm{Pt} / \mathrm{rGO}$ (b-e) $\mathrm{PtCo} / \mathrm{rGO}$ anode electrocatalysts with a $\mathrm{Pt}$ :Co ratio of $1: 1,1: 5,1: 9$ and $1: 11$ respectively in an acidic medium [19].

From Fig. 7 it is seen that the onset potential is shiftetd negatively by $121 \mathrm{mV}$ in case of $\mathrm{PtCo} / \mathrm{rGO}$ electrocatalyst with a $\mathrm{Pt}: \mathrm{Co}$ ratio of $1: 9(0.378 \mathrm{mV})$ in comparison to that observed for rGO supported Pt $(0.499$ $\mathrm{mV}$ ) and this is mainly due to the lower adsorption of $\mathrm{CO}$ on active Pt sites [99].

\section{Long term stability of PtCo/rGO electrocatalysts}

The electrochemical stability of the anode electrocatalyst in a DMFC is another important parameter for their use practical applications such as portable electronic devices including laptops, mobiles, lithium-ion batteries and other electronic devices. The cartridges prepared from methanol fuel cell have an advantage in fuel transport over others in that they are easier to handle than other hydrogen storage media. However, because of the poor performance of the anode electrocatalysts towards MOR, the commercialization of DMFC has been impeded as compared with other hydrogen/air systems. It has been found that that the Pt-based electrocatalysts prepared in the present work show reasonable electrochemical activity as well as the higher durability in comparison to commercially available $\mathrm{Pt} / \mathrm{C}$ as all the electrocatalysts exhibited much higher residual current density after a 


\section{Advanced Materials Letters www.vbripress.com/aml}

certain fixed time. The long-term stability of $\mathrm{Pt} / \mathrm{rGO}$ and as synthesized Pt based electrocatalysts with different $\mathrm{Pt}$ and Co ratio was analyzed using chronoamperometry (CA) technique. This technique is used to explore the ability of the anode electrocatalyst having resistant towards $\mathrm{CO}$ and other species adsorbed on $\mathrm{Pt}$ active surfaces. The current density vs time curves are shown in Fig. 8 carreid out in acidic medium at a constant potential for a fixed time.

From all these curves it is seen that current density for all the catalysts decreases rapidly at the initial stage mainly due to the adsorption of $\mathrm{CO}_{\text {ads }}$ and other poisoning species formed during MOR on the the surface of Pt and thereafter decreases gradually until and a quasiequilibrium state is reached. From Fig. 8 it is seen that during the whole time of $1000_{\mathrm{s}}$ a residual current density of 22.43, 21.044, 14.87, 2.22 and $0.092 \mathrm{~mA} / \mathrm{cm}^{2}$ was exhibited for $\mathrm{PtCo} / \mathrm{rGO}$ anode electrocatalysts with a Pt:Co ratio of 1:1, 1:5, 1:9, 1:11 and rGO supported Pt respectively. The residual current density in case of rGO supported PtCo electrocatalyst with a Pt:Co ratio of 1:9 is comparatively higher than those exhibited by other electrocatalysts indicating the higher electrochemical activity as well stability of this electrocatalyst towards MOR.

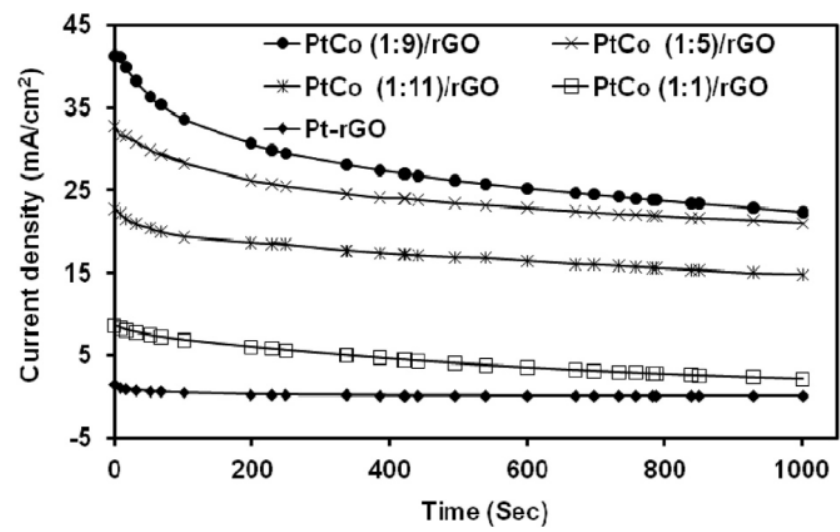

Fig. 8. Current density vs time curves of $\mathrm{Pt} / \mathrm{rGO}$ and $\mathrm{PtCo} / \mathrm{rGO}$ catalysts with different $\mathrm{Pt}$ :Co ratio in $2 \mathrm{M} \mathrm{CH} \mathrm{CH}_{3} \mathrm{OH}$ and $1 \mathrm{M} \mathrm{H}_{2} \mathrm{SO}_{4}$ at $0.7 \mathrm{~V}[\mathbf{1 9}]$.

Fig. 9 shows the electrochemical behavior of the as synthesized electrocatalysts using electrochemical impedance spectroscopy (EIS), which consists of two parts.i) in the high frequency region it is a semicircle and ii) in the low frequency region almost a straight line with a slop. The diameter of the semicircle of Nyquist plots ( $Z_{\text {im }}$ vs $Z_{\text {real }}$ gives an information about the resistance to charge transfer $\left(\mathrm{R}_{\mathrm{CT}}\right)$ taking place at the electrode-solution interface.

From this figure it is seen that the $\left(\mathrm{R}_{\mathrm{CT}}\right)$ values was much lower $(8.5 \Omega)$ in case of $\mathrm{PtCo} / \mathrm{rGO}$ catalyst having a Pt:Co molar ratio of $1: 9$ as compared to other compositions of $\mathrm{Pt}$ and $\mathrm{Co}$ in $\mathrm{PtCo} / \mathrm{rGO}$ catalysts as well as $\mathrm{Pt} / \mathrm{rGO}$ indicating a faster charge transfer in this electrode-solution/electrolyte interface, which in turn reveal the higher electrochemical activity of this electrocatalyst.

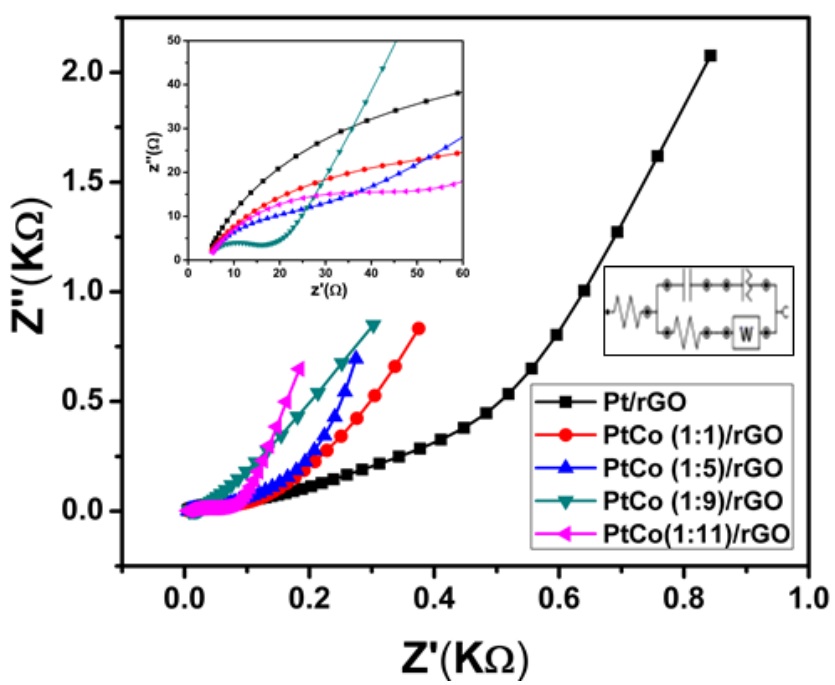

Fig. 9. Nyquist plots of $\mathrm{Pt} / \mathrm{rGO}$ and as synthesized electtrocatalysts from $0 \mathrm{~K} \Omega$ to $1 \mathrm{~K} \Omega[\mathbf{1 9}]$.

\section{DMFC single cell performance}

Fig. 10 represents the electrochemical performance of the as synthesized electrocatalysts in a single DMFC cell carried out at $100{ }^{\circ} \mathrm{C}, 1$ bar pressure and $2 \mathrm{M} \mathrm{CH}_{3} \mathrm{OH}$. From this figure it is noticed that a maximum power density of $118.4 \mathrm{~mW} / \mathrm{cm}^{2}$ is exhibited by $\mathrm{PtCo} / \mathrm{rGO}$ electrocatalyst having a Pt:Co ratio of 1:9 and is much higher to other combinations of $\mathrm{Pt}$ and $\mathrm{Co}$ in $\mathrm{PtCo} / \mathrm{rGO}$ electrocatalysts and nearly 3 times higher to that exhibited by commercial $\mathrm{Pt} / \mathrm{C}\left(42 \mathrm{~mW} / \mathrm{cm}^{2}\right)$ and thus has a great advantage in the fabrication of anode for a DMFC [62]. The details of power densities exhibited by $\mathrm{PtCo} / \mathrm{rGO}$ electrocatalysts with different $\mathrm{Pt}: \mathrm{Co}$ ratio is reported earlier [19].

The research work done using PtCo nanoparticles supported on different support materials reported by other researchers is compared with work reported in this paper reveals the excellent catalytic activity of as-synthesized rGO suppored PtCo electrocatalyst with a Pt:Co molar ratio of 1:9 and represented in Table 2.

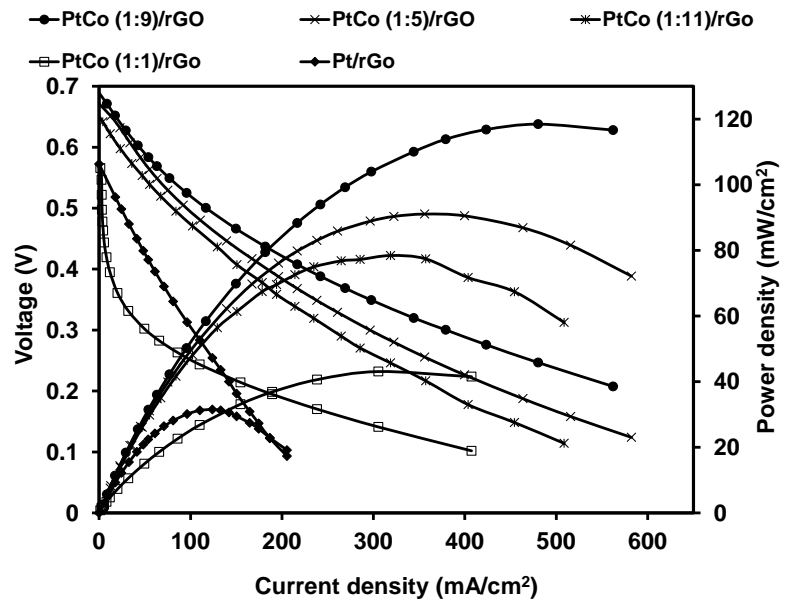

Fig. 10. Characteristic of a DMFC cell showing cell voltage, current densit and power density for $\mathrm{Pt} / \mathrm{rGO}$ and $\mathrm{PtCo} / \mathrm{rGO}$ electrocatalysts with different Pt:Co ratio [19]. 


\section{Advanced Materials Letters www.vbripress.com/aml}

Table 2. Comparison of electrochemical activity of PtCo anode electrocatalysts supported on various support materials.

\begin{tabular}{llllcl}
\hline $\begin{array}{l}\text { S. } \\
\text { No }\end{array}$ & Electrode & $\begin{array}{l}\text { Scan } \\
\text { rate } \\
\text { mV/s }\end{array}$ & $\begin{array}{l}\text { ECSA } \\
\left(\mathbf{m}^{2} / \mathbf{g}\right)\end{array}$ & $\begin{array}{c}\text { Maximum } \\
\text { anodic current } \\
\text { density } \\
\left(\mathbf{m A} / \mathbf{c m}^{2}\right) \text { or } \\
\text { mass activity } \\
(\mathbf{m A} / \mathbf{m g} \mathbf{~ P t})\end{array}$ & Ref \\
\hline 1. & $\mathrm{PtCo} / \mathrm{EG}$ & 50 & 55.75 & $525.08(\mathrm{~mA} / \mathrm{mg})$ & 27 \\
2. & $\mathrm{Pt}_{2}-\mathrm{Co} / \mathrm{G}$ & 50 & 72.3 & $106.8(\mathrm{~mA} / \mathrm{mg})$ & 133 \\
3. & $\mathrm{PtCo} / \mathrm{G}$ & 20 & 75.8 & $35.8\left(\mathrm{~mA} / \mathrm{cm}^{2}\right)$ & 13 \\
4. & $\mathrm{PtCo} / \mathrm{C}$ & 5 & 95.74 & $4.04\left(\mathrm{~mA} / \mathrm{cm}^{2}\right)$ & 134 \\
5. & $\mathrm{Pt}{ }_{2} \mathrm{Co} / \mathrm{CNT}$ & 50 & 112.5 & $14\left(\mathrm{~mA} / \mathrm{cm}^{2}\right)$ & 135 \\
6. & $\mathrm{PtCo} / \mathrm{rGO}$ & 25 & 113.8 & $3.8\left(\mathrm{~mA} / \mathrm{cm}^{2}\right)$ & 103 \\
7. & $\mathrm{PtCo} / \mathrm{LD}-\mathrm{CNT}$ & 20 & 106.0 & $428.0\left(\mathrm{~mA} / \mathrm{mg}^{2}\right)$ & 136 \\
8. & $\mathrm{PtCo} / \mathrm{S}-\mathrm{doped}$ & 20 & 129.5 & $1302.1\left(\mathrm{~mA} / \mathrm{mg}^{2}\right)$ & 137 \\
& $\mathrm{CNT}$ & & & & \\
9. & $\mathrm{PtCo}(1: 9) / \mathrm{rGO}$ & 20 & 320.08 & $38.02\left(\mathrm{~mA} / \mathrm{cm}^{2}\right)$ & 19 \\
\hline
\end{tabular}

Electrochemical activity of the electrocatalysts as a function of methanol concentration

It has been observed that methanol cross over from the anode to the cathode in a DMFC through PEM is one of the major problems. As a result of this methanol cross over a mixed potential is observed at the cathode resulting in the reduction in the overall cell voltatge [104]. In most of the cases of passive DMFCs 1.0 to $2.0 \mathrm{M}$ methanol concentration is generally used in order to obtain highest anodic current density or power density [105] and Park et. al. $[\mathbf{1 0 6 , 1 0 7 ]}$ observed the maximum efficiency of a DMFC at 4.0 M methanol concentration. Therefore, in the present work this problem was also undertaken to examine the performance of a DMFC as a function of methanol concentration [26]. It ahs already been observed in our earlier work on MOR that using a Pt:Co ratio of 1:9 in a PtCo alloy anchored on rGO a maximum anodic current density is achieved as compared to other combinations of $\mathrm{Pt}$ and $\mathrm{Co}$ in the PtCo alloy [19]. Therefore, in our subsequent experiments we have used this combination of Pt:Co in the PtCo alloy supported on rGO for the study of MOR at different methanol concentration. The CV curves showing the MOR at different methanol concentration using a comm. Pt/C and the as-synthesized $\mathrm{PtCo} / \mathrm{rGO}$ electrocatalyst with a Pt:Co ratio of 1:9 in acidic medium are represented in Fig. 11.
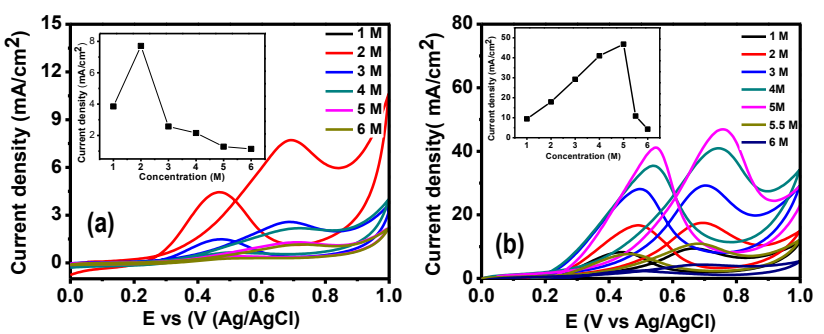

Fig. 11. CV curves observed for (a) $\mathrm{Pt} / \mathrm{C}$ (b) $\mathrm{PtCo} / \mathrm{rGO}$ with a $\mathrm{Pt}: \mathrm{Co}$ of 1:9 using $\mathrm{CH}_{3} \mathrm{OH}$ of $1-6 \mathrm{M}$ and a scan rate $20 \mathrm{mV} / \mathrm{s}$. The inset in the $\mathrm{CV}$ curves exhibits the variation of anodic peak current density at different methanol concentration [26].
It has been observed from Fig. 11(a) that using a comm $\mathrm{Pt} / \mathrm{C}$ catalyst a maximum anodic current density of $\left(7.71 \mathrm{~mA} / \mathrm{cm}^{2}\right)$ was exhibited in a $2 \mathrm{M}$ methanol whereas a Pt/C catalyst in a $2 \mathrm{M}$ methanol concentration, whereas in case of $\mathrm{PtCo} / \mathrm{rGO}$ with a Pt:Co molar ratio of $1: 9$, the anodic current density increases from 9.38 to $46.8 \mathrm{~mA} / \mathrm{cm}^{2}$ as the concentration of methanol increases from $1 \mathrm{M}$ to $5 \mathrm{M}$ and after that it decreases to $4 \mathrm{~mA} / \mathrm{cm}^{2}$ at $6 \mathrm{M}$ methanol. The electrochemical activity comparison for comm Pt/C and as-synthesized $\mathrm{rGO}$ supported $\mathrm{PtCo}$ alloy catalyst with a Pt:Co of 1:9 under a scanning rate of $20 \mathrm{mV} / \mathrm{s}$ and a $5 \mathrm{M} \mathrm{CH}_{3} \mathrm{OH}$ is represented in Fig. 12 by Linear sweep voltammetry curves.

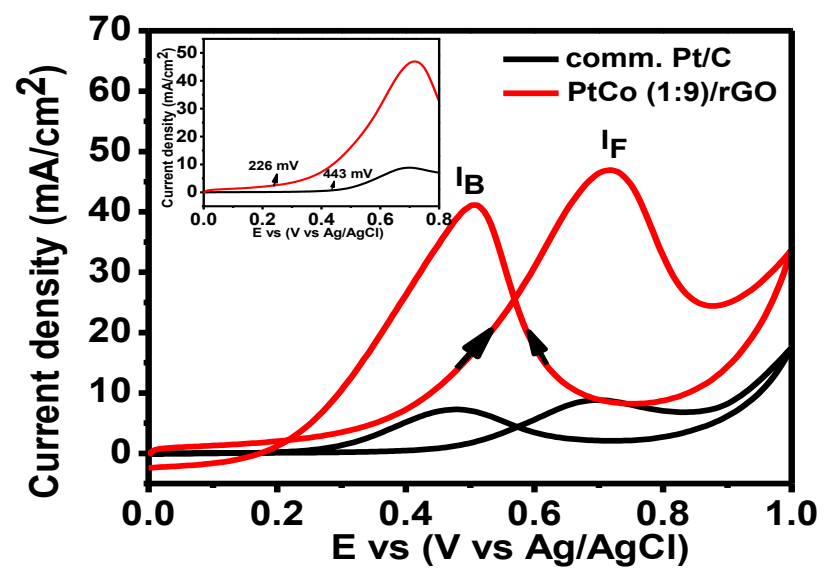

Fig. 12. $\mathrm{CV}$ curves obtained for a comm. $\mathrm{Pt} / \mathrm{C}$ and $\mathrm{PtCo} / \mathrm{rGO}$ catalyst having a molar ratio of $1: 9$ in a $1 \mathrm{M} \mathrm{H}_{2} \mathrm{SO}_{4}+5 \mathrm{M} \mathrm{CH}_{3} \mathrm{OH}$ solution saturated with nitrogen and the inset shows the LSV curves [26].

It is also seen that peak anodic current density of the as-synthesized $\mathrm{PtCo} / \mathrm{rGO}$ electrocatalyst is $\sim 6$ times high to that of $\mathrm{Pt} / \mathrm{C}$ in a $5 \mathrm{M} \mathrm{CH}_{3} \mathrm{OH}$ indicating efficient MOR for this catalyst. Further, the $\mathrm{I}_{\mathrm{F}} / \mathrm{I}_{\mathrm{B}}$ ratio provides the information about the resistance of the electrocatalysts towards $\mathrm{CO}$ and this ratio for the as-synthesized $\mathrm{PtCo} / \mathrm{rGO}$ electrocatalyst having Pt:Co ratio of $1: 9$ is found to be higher (1.13) in comparison to $\mathrm{Pt} / \mathrm{C}$ thus indicating its higher CO tolerance. Also, from the inset of Fig. 12, it is noticed that the onset potential of the as-synthesized anode electrocatalyst is negatively shifted by $200 \mathrm{mV}$ in comparison to commercial $\mathrm{Pt} / \mathrm{C}$ showing that the MOR is taking place at lower potential using the $\mathrm{PtCo} / \mathrm{rGO}$ catalyst. It is likely at methanol concentration higher than $5 \mathrm{M}$, the Pt active sites necessary for MOR are saturated with methanol molecules and also its surface contamination by intermediate species during MOR 108]. The stability of the $\mathrm{PtCo} / \mathrm{rGO}$ electrocatalyst having Pt:Co of 1:9 in a $5 \mathrm{M} \mathrm{CH}_{3} \mathrm{OH}$ and that of a Pt/C in a $2 \mathrm{M}$ $\mathrm{CH}_{3} \mathrm{OH}$ is as measured using current density - time curves and shown in Fig. 13. From this figure it is seen that the residual anodic current density at the end of the experiment is much higher in case of $\mathrm{rGO}$ supported PtCo alloy electrocatalyst in comparison with commercial $\mathrm{Pt} / \mathrm{C}$ thus confirming the higher electrochemical stability and durability of the assynthesized electrocatalyst. 


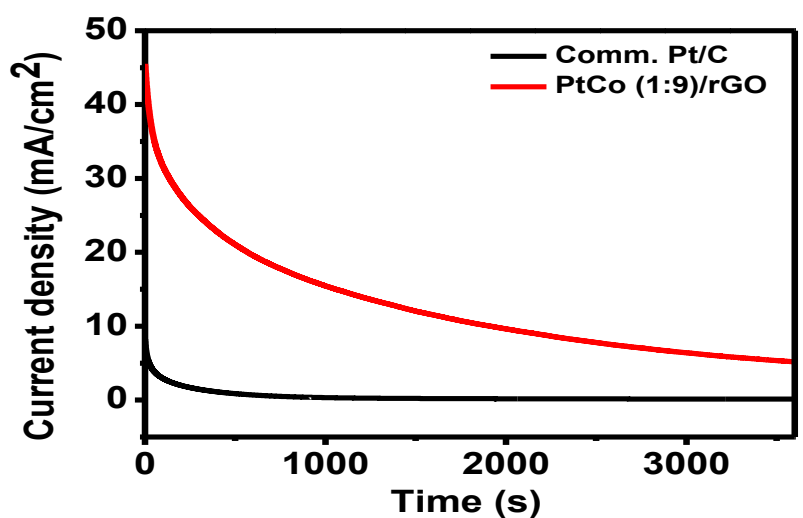

Fig. 13. Current density vs time curves at $0.7 \mathrm{~V}$ for (a) comm. Pt/C; (b) $\mathrm{PtCo} / \mathrm{rGO}$ catalyst having Pt:Co of 1:9 in $1 \mathrm{M} \mathrm{H}_{2} \mathrm{SO}_{4}$ and $2 \mathrm{M} \mathrm{CH}_{3} \mathrm{OH}$ for 3600s [26].

The long-term poisoning rate is evaluated using the equation as mentioned below 75]:

$$
\delta\left(\frac{\%}{S}\right)=\frac{100}{I_{o}} \times\left(\frac{d I}{d T}\right)_{t>500 s}
$$

where $(\mathrm{dI} / \mathrm{dt})_{t>500 \mathrm{~s}}$ is the slope of the linear portion of the current decay, and $\mathrm{I}_{\mathrm{o}}$ is the residual current density. From the above equation it was calculated that the poisoning rate of $\mathrm{PtCo} / \mathrm{rGO}$ anode electrocatalyst having a Pt:Co ratio of $1: 9(0.021 \% / \mathrm{sec})$ is much much lower $(\sim 42 \%)$ as compared to Pt nanoparticles $(0.05 \% / \mathrm{s})$. The lower value of the poisoning rate for as-synthesized $\mathrm{PtCo} / \mathrm{rGO}$ catalyst also implies the high catalytic activity of this catalyst towards MOR in addition to its more tolerance towards $\mathrm{CO}$ and other intermediates species formed during methanol oxidation that are responsible for the deactivation of $\mathrm{Pt}$ active sites.

Faradaic efficiency of a DMFC a PtCo/rGO electrocatalyst having Pt:Co ratio of 1:9 and comm Pt/C at different methanol concentration was calculated using the following equation [104].

$$
\begin{aligned}
& \text { Discharging capacity (Ah) } \\
& \eta=
\end{aligned}
$$

$$
\eta=\frac{\int_{0}^{t} i(t) d t}{6 C_{M} V_{M} F},
$$

In this equation, $\mathrm{t}$ is discharging time, $i(\mathrm{t})$ is discharging current, $C_{M}$ is concentration of methanol, $V_{M}$ is the volume of methanol and $\mathrm{F}$ is Faraday constant. From this equation is calculated that the highest Faraidic efficiency is only of about $0.05 \%$ for commPt/C at $2 \mathrm{M}$ $\mathrm{CH}_{3} \mathrm{OH}$, whereas the as-synthesized $\mathrm{PtCo} / \mathrm{rGO}$ having a Pt:Co ratio of 1:9 showed a much higher value of Faradiac efficiency $(\sim 60 \%)$ in a $5 \mathrm{M}$ methanol. The Faradaic efficiency of comm Pt/C and that exhibited by the assynthesized $\mathrm{PtCo} / \mathrm{rGO}$ electrocatalyst having Pt:Co ratio of 1:9 are shown in the bar diagram of Fig. 14(a) and Fig. 14(b) respectively clearly showing that enhanced Faradiac efficiency of the as-synthesized electrocatalyst a methanol concentration of $5 \mathrm{M}$ indicating minimum crossover even at this concentration, thus exhibiting high electrochemical performance.
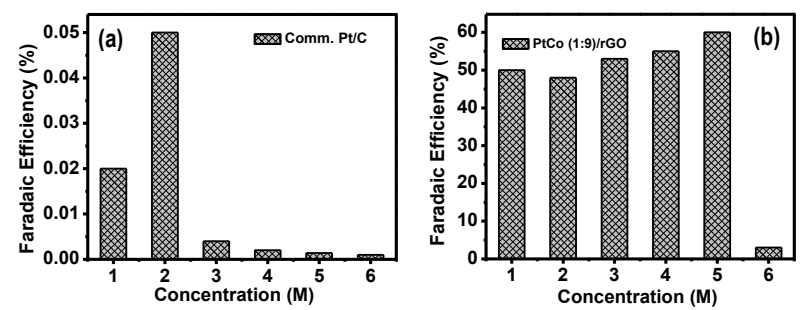

Fig. 14. Bar diagrams showing the Faradaic efficiency of half cell DMFC at different conc of $\mathrm{CH}_{3} \mathrm{OH}$ for (a) comm. Pt/C and (b) $\mathrm{PtCo} / \mathrm{rGO}$ electrocatalyst having Pt:Co of 1:9 [26].

Further, it was observed that the Faradaic efficiency at $2 \mathrm{M} \mathrm{CH}_{3} \mathrm{OH}$ is also much higher $(46 \%)$ for the assynthesized $\mathrm{PtCo} / \mathrm{rGO}$ electrocatalyst in comparison to that observed for commercial $\mathrm{Pt} / \mathrm{C}$ at this methanol concentration.However, beyond a methanol concentration of $5 \mathrm{M}$ the Faradaic efficiency of the as-synthesized $\mathrm{PtCo} / \mathrm{rGO}$ catalyst is also found to decrease from 60 to only $6 \%$ at $6 \mathrm{M}$, which may be explained by the fact at methanol concentration higher than $5 \mathrm{M}$, no more active $\mathrm{Pt}$ sites are available for MOR due to their saturation. The Faradaic efficiency observed by Liu et. al. [100] is only $22 \%$ in a $5 \mathrm{M}$ methanol concentration using passive DMFC using passive DMFC; much lower that that observed for the as-synthesized catalyst at $5 \mathrm{M} \mathrm{CH}_{3} \mathrm{OH}$.

The next set of experiments were carried out in order to test the electrochemical performance of a complete cell for the as-synthesized PtCo/rGO electrocatalyst having $\mathrm{Pt}: \mathrm{Co}$ ratio of $1: 9$ and comm $\mathrm{Pt} / \mathrm{C}$ catalyst at different temperatures and methanol concentration. The results of these CV results are shown in Fig. 15 (a \& b) shows the for both the anode catalysts which shows the CV curves between the cell voltage and current as well as power density. From these curves it is noticed that using the as synthesized $\mathrm{PtCo} / \mathrm{rGO}$ catalyst having a Pt:Co ratio of $1: 9$, the best DMFC cell performance was achieved with a $5 \mathrm{M}$ methanol concentration, $100^{\circ} \mathrm{C}$ and a catalyst loading of $3 \mathrm{mg} / \mathrm{cm}^{2}$. It is also seen that the maximum powder density exhibited by this electrocatalyst $\left(136.8 \mathrm{~mW} / \mathrm{cm}^{2}\right)$ was almost 3 times higher to that exhibited by comm Pt/C $\left(\left(48.03 \mathrm{~mW} / \mathrm{cm}^{2}\right)\right.$.
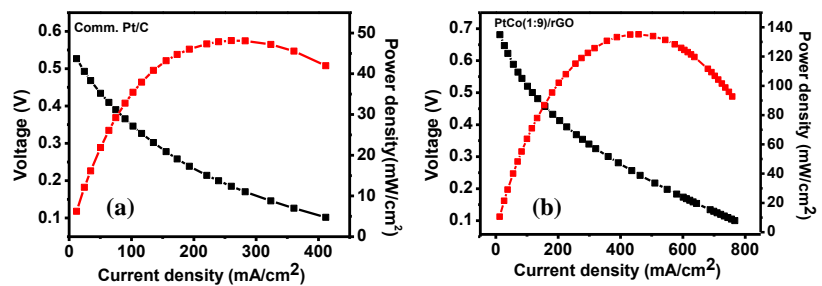

Fig. 15. Cell performance of a DMFC using a) Comm Pt/C and b) assynthesized $\mathrm{PtCo} / \mathrm{rGO}$ catalysts having a Pt:Co ratio of 1:9. The other operating parameters are: $\mathrm{P}_{\text {methanol }}=1 \mathrm{bar}$, flow rate $=1 \mathrm{~mL} / \mathrm{min} ; \mathrm{O}_{2}$ flow rate $=200 \mathrm{sccm}$; Electrolyte: Nafion 117 membrane. Methanol conc used for $\mathrm{Pt} / \mathrm{C}$ was $2 \mathrm{M}$ and that for $\mathrm{rGO}$ supported PtCo catalyst was $5 \mathrm{M}$ [26]. 


\section{Advanced Materials Letters www.vbripress.com/aml}

It has been observed that MOR at anode electrocatalyst is also temperature dependent in addition to methanol concentration. Therefore, another series of experiments were carried out by varying the cell temperature from 100 to $70^{\circ} \mathrm{C}$ for $\mathrm{PtCo} / \mathrm{rGO}$ electrocatalyst having a $\mathrm{Pt}: \mathrm{Co}$ ratio of 1:9. Fig. 16(a) shows the $\mathrm{CV}$ results of MOR obtained using this electrocatalyst at different methanol concentration ( $1 \mathrm{M}$ to $5 \mathrm{M}$ ) and those obtained at different temperatures in a 5 M methanol are represented Fig. 16(b). It is observed from the temperature dependent MOR that a maximum power density of $136.8 \mathrm{~mW} / \mathrm{cm}^{2}$ was obtained at the cell temperature of $100^{\circ} \mathrm{C}$ and as the cell temperature decreases to $70^{\circ} \mathrm{C}$, the power density also decreases to $\sim 93.7 \mathrm{~mW} / \mathrm{cm}^{2}$ as shown in Fig. 16(b).

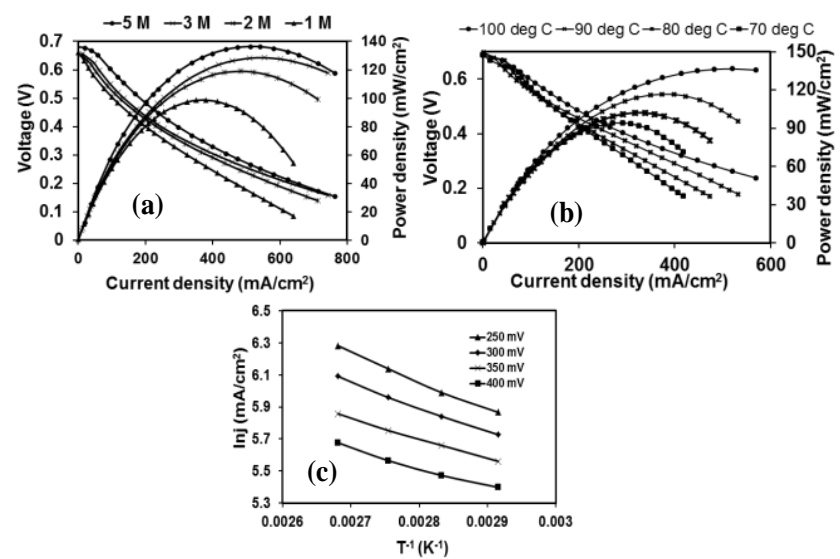

Fig. 16. $\mathrm{CV}$ curves for $\mathrm{PtCo} / \mathrm{rGO}$ electrocatalyst having a molar ratio of $1: 9$ (a) at $1 \mathrm{M}-5 \mathrm{M}$ methanol; (b) at temperatures $100-70{ }^{\circ} \mathrm{C}$ and (c) Arrhenius plots at 250, 300, 350 and $400 \mathrm{mV}$ potentials [26].

The Arrhenius curves for $\mathrm{PtCo} / \mathrm{rGO}$ electrocatalyst having a Pt:Co molar ratio of $1: 9$ at four different voltages varied from $250 \mathrm{mV}$ to $400 \mathrm{mV}$ at an interval of $50 \mathrm{mV}$ are represented in Fig. 16(c) and the results are shown in Table 3. It was observed that the activation energy for the as-synthesized electrocatalyst was only $9.843 \mathrm{kj} / \mathrm{mole}$ at $400 \mathrm{mV}$ and is significantly lower to those observed for commercial $\mathrm{Pt} / \mathrm{C}(70 \mathrm{kj} / \mathrm{mol})$ and $\mathrm{PtRu} / \mathrm{C} \quad(33.6 \mathrm{kj} / \mathrm{mole}) \quad$ [109], thereby confirming again the better electrochemical performance of the assynthesized $\mathrm{PtCo} / \mathrm{rGO}$ electrocatalyst having 1:9 of $\mathrm{Pt}: \mathrm{Co}$ molar ratio.

Table 3. Activation energy of PtCo/rGO electrocatalyst having a Pt:Co ratio of 1:9 at four values of potentials.

\begin{tabular}{ccc}
\hline Voltage $(\mathbf{m V})$ & Slope $\left(\mathbf{l n} \mathbf{j} / \mathbf{T}_{\mathbf{2}} \mathbf{- 1}^{-\mathbf{T}} \mathbf{T}_{\mathbf{1}}^{-\mathbf{1}}\right)$ & $\mathbf{E}_{\mathbf{a}}(\mathbf{K J} \mathbf{J} / \mathbf{m o l})$ \\
\hline 250 & 1783.8 & 14.712 \\
300 & 1547.5 & 12.86 \\
350 & 1365 & 11.348 \\
400 & 1184 & 9.843 \\
\hline
\end{tabular}

Thus the overall results shows that $\mathrm{PtCo} / \mathrm{rGO}$ electrocatalyst a Pt:Co molar ratio of 1:9 exhibits a much better electrochemical activity in comparison to commercial $\mathrm{Pt} / \mathrm{C}$. This is attributed mainly due to the presence of $\mathrm{Co}$ in $\mathrm{PtCo}$ alloy nanoparticles which help in creating more $\mathrm{OH}$ species near the $\mathrm{Pt}$ surface during methanol oxidation and remove poisonous $\mathrm{CO}$ and other carbonaceous species in accordance to bi-functional mechanism $[\mathbf{6 , 2 8 , 1 0 3}]$. Thus, it is confirmed from the above series of experiments that the as-synthesized $\mathrm{PtCo} / \mathrm{rGO}$ electrocatalyst not only exhibits excellent electrochemical performance at 2M methanol concentration as seen in Section 3.1 but also at higher concentrations (up to $5 \mathrm{M}$ ) and therefore, can be used in the fabrication of anode in a DMFC for MOR at lower onset potentials.

From the above results it is confirmed that the addition of $\mathrm{Co}$ in Platinum not only enhanced the DMFC power density, lower the activation energy for MOR but also reduces its crossover towards the cathode side of the cell. The reaction pathways for methanol electro-oxidation on PtCo alloy catalyst at room temperature is more or less similar to that observed in case of PtRu alloy catalyst as reported Li and Xing [5] and are represented as follows:

$$
\begin{aligned}
& \mathrm{Pt}+\mathrm{CH}_{3} \mathrm{OH} \rightarrow \mathrm{Pt}-\mathrm{CO}_{\mathrm{ads}}+4 \mathrm{H}^{+}+4 \mathrm{e}^{-} \\
& \mathrm{Co}+\mathrm{H}_{2} \mathrm{O} \rightarrow \mathrm{Co}(\mathrm{OH})_{\mathrm{ads}}+\mathrm{H}^{+}+\mathrm{e}^{-} \\
& \mathrm{PtCO}_{\mathrm{ads}}+\mathrm{Co}(\mathrm{OH})_{\mathrm{ads}} \rightarrow \mathrm{Pt}+\mathrm{Co}+\mathrm{CO}_{2}+\mathrm{H}^{+}+\mathrm{e}^{-}
\end{aligned}
$$

The alloying of $\mathrm{Pt}$ with Co nanoparticles in the assynthesized $\mathrm{PtCo} / \mathrm{rGO}$ electrocatalyst with a $\mathrm{Pt}$ :Co ratio of 1:9 helps in the transfer the charge from Co to $\mathrm{Pt}$, removes the adsorbed $\mathrm{CO}$ from Pt surface and thus more and more sites are available for the continuous MOR.

The MOR which in turn the performance of the DMFC is increased by increasing the molar ratio of cobalt in PtCo alloy upto I:9 of Pt:Co. However the overall performance was found to decrease if the molar ratio of Pt:Co was increased beyond 1:9 and it is seen that the MOR is much lower in case of $\mathrm{PtCo} / \mathrm{rGO}$ electrocatalyst having a molar ratio of $1: 11$ as in this electrocatalyst the active Pt sites are believed to be much lower as compared to that in $\mathrm{PtCo} / \mathrm{rGO}$ electrocatalyst having a molar ratio of 1:9. Thus a optimum concentration of $\mathrm{Co}$ in the PtCo alloy plays a significantly role in enhancing the MOR and only its optimum concentration leads to the excellent performance in a DMFC. A concentration of cobalt (higher than 1:9) in the PtCo alloy leads to deterioration in the electrochemical activity of the catalyst and hence the overall cell performance because of the less availability of $\mathrm{Pt}$ sites and a maximum power density of $136.8 \mathrm{~mW} / \mathrm{cm}^{2}$ at $100^{\circ} \mathrm{C}$ was achieved using the as-synthesized $\mathrm{PtCo} / \mathrm{rGO}$ anode electrocatalyst having a Pt:Co ratio of $1: 9$ with $2.5 \mathrm{mg} / \mathrm{cm}^{2}$ as catalyst loading.

\section{Electro-oxidation of methanol using PtCu alloy nanoparticles supported on nitrogen doped $\mathrm{rGO}$}

It has been already been demonstrated Pt performs highest catalytic performance in the electooxidation of methanol both in acidic as well as in alkaline medium because of its outstanding properties. Although, it has the best capability to dehydrogenate methanol to $\mathrm{CO}$ and other intermediates 


\section{Advanced Materials Letters www.vbripress.com/aml}

as shown in Fig. 1, it has difficulty in activation water molecules. Also because of its high cost and its surface deactivation due to the adsorption of $\mathrm{CO}$ and other carbonaceous species, it is generally alloyed with cheap 3d-transition metals as already mentioned earlier. All these metals not only modify the electronic structure of $\mathrm{Pt}$ by increasing it d-band vacancy, more favorable Pt-Pt distance, but also activate water molecules thereby producing more $\mathrm{OH}$ species near the active $\mathrm{Pt}$ sites and help in removing the $\mathrm{CO}_{\text {ads }}$ from the Pt surface. Further, the ECSA of $\mathrm{Pt}$ in these bimetallic alloys is much higher than pure Pt metal. It has recently been found that $\mathrm{Cu}$ also exhibit water activation and other related reaction, such as the electro-reduction of $\mathrm{CO}_{2}[\mathbf{1 1 0}]$. Therefore, the alloy of $\mathrm{Pt}$ with $\mathrm{Cu}$ are considered to be effective electrocatalysts catalysts which are resistant to $\mathrm{CO}_{\mathrm{ads}}$ and similar intermediates [111]. Therefore, $\mathrm{PtCu}$ alloy catalysts supported on different support materials including multiwalled carbon nanotubes, carbon black and rGO etc have recently attracted a great attention for MOR both in acidic as well as in alkaline medium $[96,99,110,112-$ 117] etc. and so on. Zhong et. al. [112] have observed the mass activity of $\mathrm{Pt}: \mathrm{Cu}$ in the mass ratio of 1:025 supported on multiwalled carbon nanotubes (CNTs) is $~ 2.5$ times higher than that observed for Pt/CNTs. Khan et. al. [116] have studied MOR using PtCu alloy catalyst supported on PC-950 (15\%: 15\%) and observed the anodic current density of $28.3 \mathrm{~mA} / \mathrm{cm}^{2}$ which is higher to those of $\mathrm{Pt} / \mathrm{C}$ catalyst $\left(20 \mathrm{~mA} / \mathrm{cm}^{2}\right)$. Similarly, according to Wang et. al. [113], the mass activity of $\mathrm{PtCu}_{2}$ nanoparticles supported on carbon is 3.3 times higher than that of $\mathrm{Pt} / \mathrm{C}$. In the paper reported by Du et. al. [99] the anodic current density $\left(24.6 \mathrm{~mA} / \mathrm{cm}^{2}\right)$ was nearly 4.4 times higher than of $\mathrm{Pt} / \mathrm{C}$. However, most of the researchers have used rGO as the support material for $\mathrm{PtCu}$ alloy nanoparticles [113-115] and observed the electrochemical activity of their assynthesized catalysts to be much higher that that exhibited by commercial Pt/C. Very recently, rGO supported $\mathrm{PtCu}$ alloy nanoparticles, Vulcan XC-72 and the composite of rGO and vulcanized carbon have been studied by Yilmaz et. al. [118] for fuel cell reactions and it is reported that using $\mathrm{Cu}_{45} \mathrm{Pt}_{55}$ alloy nanoparticles supported on a hybrid of rGO and $\mathrm{VC}$ exhibited a much higher catalytic activity and a power density of $480 \mathrm{~mW} / \mathrm{cm}^{2}$ in PEMFC. Instead of $\mathrm{PtCu}$ alloy nanoparticles few researchers have used $\mathrm{PtCu}$ nanocages, nanosheets and even thin nanowires [115] for MOR or ethanol oxidation reaction (EOR) in alkaline medium and obtained a anodic current density of $0.06 \mathrm{~A} / \mathrm{cm}^{2}$. In most of the research workon MOR, rGO is used as the supporting material because of its outstanding properties [96]. Further, its properties are superior to CNTs, as its one atomic-thick graphene sheets with a 2D planar geometry helps in better transport of electrons. In the present work nitrogen doped reduced graphene oxide (N-rGO) is used as a conducting support material for anchoring $\mathrm{PtCu}$ nanoparticles having different $\mathrm{Pt}: \mathrm{Cu}$ molar ratio in $\mathrm{PtCu}$ alloy for $\mathrm{MOR}$ in acidic medium at room temperature [33].
$\mathrm{N}$-rGO has already been found to be promising candidates for lithium-ion battery anodes as nitrogen provides more electron cloud density and conductivity [120] and also for methanol electrocatalytic oxidation using $\mathrm{Pt}$ and PtCo alloys $[\mathbf{5 6 , 1 2 1 , 1 2 2 ]}$. It has been found that the enhanced MOR using the as-synthesized $\mathrm{PtCu} / \mathrm{N}-\mathrm{rGO}$ electrocatalysts is mainly due to the strong interfacial interaction (SMS) between the nitrogen of rGO and $\mathrm{PtCu}$ nanoparticles. As a result of this the adsorption of $\mathrm{CO}$ on active $\mathrm{Pt}$ sites is minimized and hence faster MOR reaction kinetics is observed. This reduces the fractional converage of $\mathrm{CO}$ on $\mathrm{Pt}$ surface, thereby creating more active Pt sites for MOR; thus, faster reaction kinetics is believed. From the various electrochemical measurements, it was found that $\mathrm{PtCu}(1: 2) / \mathrm{N}-\mathrm{rGO}$ electrocatalyst exhibits much higher electrochemical activity than those of other combinations of $\mathrm{Pt}$ and $\mathrm{Cu}$ in $\mathrm{PtCu}$ alloy. Therefore, most of the electrochemical measurements were limited to $\mathrm{PtCu}(1: 1) / \mathrm{N}-\mathrm{rGO}$ and $\mathrm{PtCu}(1: 2) / \mathrm{N}-\mathrm{rGO}$ catalysts and their results were compaired with pure $\mathrm{Pt} / \mathrm{N}-\mathrm{rGO}$ and $\mathrm{Pt} / \mathrm{C}$ electrocatalysts.

Fig. 17 shows the schematic diagram for the preparation of $\mathrm{PtCu}$ nanoparticles supported on N-rGO by thermmaly heating of melamine powder and graphene oxide (GO) powders at $900{ }^{\circ} \mathrm{C}$ followed by refluxing with the salts of $\mathrm{Pt}$ and $\mathrm{Cu}$ (in different molar ratios) in ethylene glycol at $180^{\circ} \mathrm{C}$.

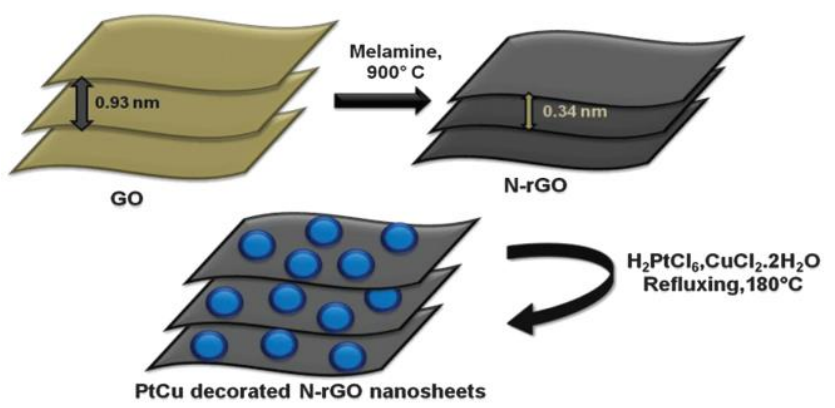

Fig. 17. Schematic diagram for synthesis of $\mathrm{PtCu} / \mathrm{N}-\mathrm{rGO}$ anode electrocatalysts [33].
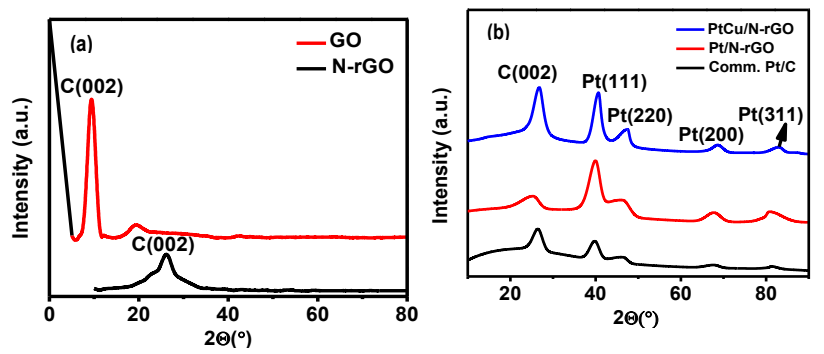

Fig. 18. XRD pattern of (a) GO and N-rGO (b) Comm Pt/C, Pt/N-rGO and $\mathrm{PtCu} / \mathrm{N}-\mathrm{rGO}[33]$.

The crystalline structure of GO and N-rGO prepared in the present work were analyzed using XRD and shown in Fig. 18(a). In the XRD pattern of GO a broad peak at $\sim 2 \theta=11.03^{\circ}$ with a ' $\mathrm{d}$ '-spacing of $0.939 \mathrm{~nm}$ is due to (002) plane of carbon and is attributed to the attachment of various functional groups during the oxidation of graphite 


\section{Advanced Materials Letters www.vbripress.com/aml}

powder and are used subsequently as bonding sites for $\mathrm{PtCu}$ alloy nanoparticles. It is also observed that in the XRD pattern of N-rGO, the XRD peak (002) of GO shifts to the higher angle $\left(2 \theta=\sim 26.02^{\circ}\right)$ from $11.03^{\circ}$ corresponding to a d-spacing of $0.343 \mathrm{~nm}$ ) after thermal annealing of $\mathrm{GO}$ with melamine powder at $\sim 900^{\circ} \mathrm{C}$ in a nitrogen atmosphere. The reduction in ' $\mathrm{d}$ ' spacing in $\mathrm{N}-\mathrm{rGO}$ is ascribed to the restoration of ordered graphitic structure in rGO. Fig. 18(b) shows the X-ray diffraction patterns of commercially available $\mathrm{Pt} / \mathrm{C}, \mathrm{Pt}$ with $\mathrm{N}$ doped rGO and $\mathrm{PtCu}$ alloy nanoparticles supported on N-rGO respectively. In $\mathrm{Pt} / \mathrm{N}-\mathrm{rGO}$ catalyst, the XRD peaks appearing at $2 \theta$ are $39.78,46.36,67.55$ and $81.33^{\circ}$ correspond to (111), (200), (220) and (311) planes, of fcc structure of Pt. However, in case of $\mathrm{PtCu}(1: 2) / \mathrm{N}-\mathrm{rGO}$ catalyst, it is seen that all the diffraction peaks due to $\mathrm{Pt}$ shift to higher $2 \theta$ angles [40.42, 47.43, 68.52 and $82.84^{\circ}$ ] for (111), (200), (220) and (311) respectively) indicating a lattice contraction as a result of incorporation of small $\mathrm{Cu}$ into the Pt sites. The highest intensity peak of Pt (111) was utilized to determine the lattice parameter ' $a$ ' in all the electrocatalysts using the following equation [112].

$$
\mathrm{a}(\mathrm{nm})=\underline{3 \kappa} \underset{2 \operatorname{Sin} \theta_{(111)}}{ }
$$

where $\lambda=0.15406 \mathrm{~nm}$, theta (111) is half the $2 \theta$ angle at maximum. Using the above equation, the ' $\mathrm{a}$ ' of $\mathrm{PtCu}$ nanoparticles supported on $\mathrm{N}-\mathrm{rGO}$ was calculated to be much smaller $(0.385 \mathrm{~nm})$ to those calculated for pure $\mathrm{Pt}$ supported on $\mathrm{N}-\mathrm{rGO}(0.391 \mathrm{~nm})$ and commercial $\mathrm{Pt} / \mathrm{C}$ $(0.394 \mathrm{~nm})$ catalysts. This is mainly due to the $\mathrm{PtCu}$ alloy formation where $\mathrm{Pt}$ atoms are replaced by smaller copper atoms thereby reducing the lattice parameters. Further, it has been observed from the XRD patterns that the peaks due to As the XRD pure $\mathrm{Pt}$ and pure $\mathrm{Cu}$ are absent in these $\mathrm{XRD}$ spectra for $\mathrm{PtCu}(1: 2) / \mathrm{N}-\mathrm{rGO}$, it confirms that the quantity of non-alloyed $\mathrm{Pt}$ and $\mathrm{Cu}$ is either very small or cannot be detected by XRD. The PtCu alloy formation was further confirmed by the fact that the XRD peaks fall in between those of pure $\mathrm{Pt}$ and $\mathrm{Cu}$. Further, the size of assynthesized $\mathrm{PtCu}(1: 2) / \mathrm{N}-\mathrm{rGO}$ and $\mathrm{Pt} / \mathrm{N}-\mathrm{rGO}$ catalysts were found to be 3 and $4 \mathrm{~nm}$ respectively from the Scherrer's equation. From the FESEM micrographs and EDS analysis (Fig. 19) of the as synthesized catalyst it is clearly seen that $\mathrm{Pt}$ and $\mathrm{Cu}$ are homogeneously distributed onto N-rGO nanosheets.

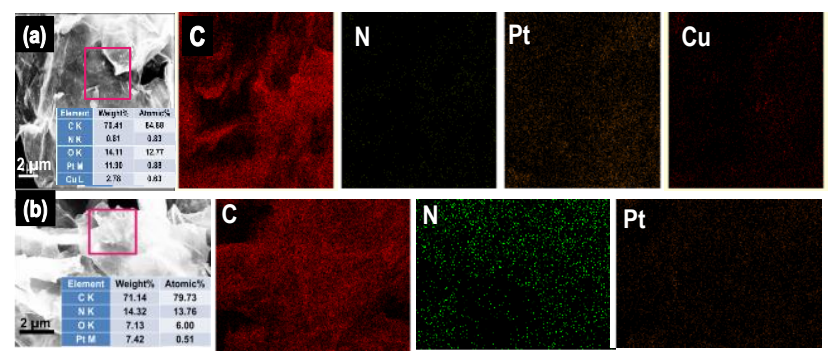

Fig. 19. FESEM micrographs (a) $\mathrm{PtCu} / \mathrm{N}-\mathrm{rGO}$ at a scale of $2 \mu \mathrm{m}$ (b) $\mathrm{Pt} / \mathrm{N}-\mathrm{rGO}$ at a scale of $2 \mu \mathrm{m}$. Right bottom inset represent the percentage composition of each element [33].
The presence of elemental $\mathrm{Pt}, \mathrm{Cu}, \mathrm{C}$ and $\mathrm{N}$ were detected in the point scan of $\mathrm{PtCu}(1: 2) / \mathrm{N}-\mathrm{rGO}$ electrocatalyst (Fig. 19a) and that in $\mathrm{Pt} / \mathrm{N}-\mathrm{rGO}$ electrocatalyst only elemental C, N and Pt were detected as shown in Fig. 19(b). The table in the insets of Fig. 19 (a\&b) depicts the EDS spectrum of as-synthesized $\mathrm{PtCu} /$ $\mathrm{N}-\mathrm{rGO}$ electrocatalyst having a Pt:Cu ratio of $1: 2$ and $\mathrm{Pt} / \mathrm{N}-$ rGO electrocalysts wherein the atomic and weight percentage of $\mathrm{C}, \mathrm{O}, \mathrm{N}, \mathrm{Pt}, \mathrm{Cu}$ are depicted indicating the confirmation of the elemental composition. Fig. 20 shows the TEM, HRTEM and SAED patterns of $(\mathbf{a}, \mathbf{b}) \mathrm{N}$-rGO, (c,d,e) $\mathrm{Pt} / \mathrm{N}-\mathrm{rGO}$ and $\quad$ (f,g,h) $\mathrm{PtCu} \quad(1: 2) / \mathrm{N}-\mathrm{rGO}$ respectively. From the TEM micrographs shown in Fig. 20(c\&f) it is seen that both $\mathrm{Pt}$ as well as $\mathrm{PtCu}$ nanoparticles are uniformly dispersed on $\mathrm{N}-\mathrm{rGO}$ nanosheets in $\mathrm{Pt} / \mathrm{N}-\mathrm{rGO}$ and $\mathrm{PtCu}(1: 2) / \mathrm{N}-\mathrm{rGO}$ electrocatalysts. However, the averthe size of $\mathrm{Pt}$ and $\mathrm{PtCu}$ nanoparticles in these electrocatalysts was around 4 and $2.5 \mathrm{~nm}$ respectively. The small average particle size of $\mathrm{PtCu}$ nanoparticles with a uniform homogeneous dispersion on the surface of nitrogen doped rGO nanosheets are also responsible for high MOR for $\mathrm{PtCu}(1: 2) / \mathrm{N}-\mathrm{rGO}$ electrocatalyst as compared to that of $\mathrm{Pt} / \mathrm{N}-\mathrm{rGO}$ electrocatalyst. These results also support the earlier observations that the small particle size of $\mathrm{PtCu}$ alloy nanoparticles and their homogeneous dispersion of N-rGO nanosheets in $\mathrm{PtCu} / \mathrm{N}-\mathrm{rGO}$ electrocatalyst are the main parameters responsible for higher MOR in comparison to $\mathrm{Pt} / \mathrm{N}-\mathrm{rGO}[\mathbf{3 7 , 1 2 3}]$. Fig. 20 also shows the TEM and HRTEM images of N-rGO, Pt/N-rGO and $\mathrm{PtCu}(1: 2) / \mathrm{N}-$ rGO catalysts.

As can be seen from Fig. 20(a), TEM images clearly reveals a folded sheet like morphology of $\mathrm{N}$ doped reduced graphene oxide, whereas a clear hexagon spot pattern depicted the hexagon graphene framework in the SAED pattern in Fig. 20(b). Fig. 20(c,d,e) are the TEM, HRTEM and SAED pattern images of $\mathrm{Pt} / \mathrm{N}-\mathrm{rGO}$ composite respectively which depicts the uniform and dense distribution of $\mathrm{Pt}$ nanoparticles onto N-rGO nanosheets. The high-resolution TEM micrograph (Fig. 21g) represents a crystalline $\mathrm{PtCu}$ alloy. The d-spacings of $\mathrm{PtCu}(111)$ is $0.218 \mathrm{~nm}$ which is in between the ' $\mathrm{d}$ ' spacing of pure $\mathrm{Pt}(111)[0.230 \mathrm{~nm}]$ and pure and $\mathrm{Cu}$ (111) $[0.209 \mathrm{~nm}]$, thus confirming the formation of $\mathrm{PtCu}$ alloy [96]. The calculated average size of $\mathrm{PtCu}$ was found to be $2.5 \mathrm{~nm}$ in $\mathrm{PtCu}(1: 2) / \mathrm{N}-\mathrm{rGO}$ and $4 \mathrm{~nm}$ in $\mathrm{Pt} / \mathrm{N}-\mathrm{rGO}$ catalysts. These results are also supported by the XRD results obtained earlier on these electrocatalysts. From the TEM images shown in Fig. 20 (c\&f) it is noticed that Pt nanoparticles are more agglomerated in case of $\mathrm{Pt} / \mathrm{N}-\mathrm{rGO}$ electrocatalyst in comparasion to that on $\mathrm{PtCu}(1: 2) / \mathrm{N}-$ rGO electrocatalyst, indicating that the size of $\mathrm{Pt}$ and its homogeneous dispersion on the N-rGO nanosheets are highly dependent on the $\mathrm{Cu}$ alloying metal. All these factors including small average particle size and their homogeneous dispersion on the N-doped rGO nanosheets reflects the higher electrochemical activity of the assynthesized $\mathrm{PtCu}(1: 2) / \mathrm{N}-\mathrm{rGO}$ electrocatalyst in the present work. 


\section{Advanced Materials Letters www.vbripress.com/aml}

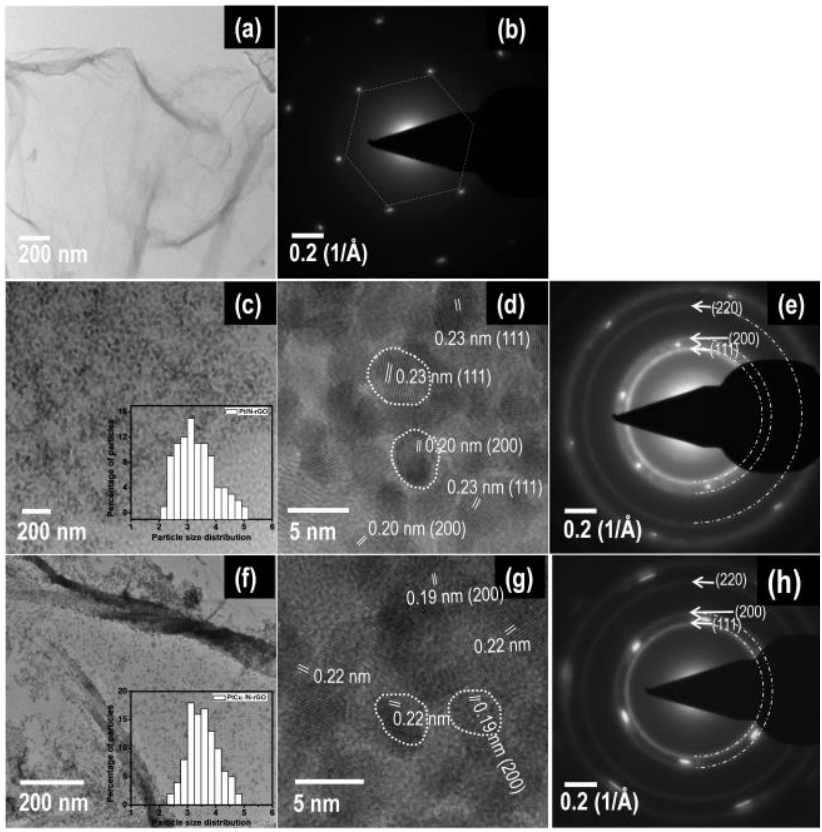

Fig. 20. TEM \& HRTEM iamges of (a \& b) N-rGO, (c, d, e) Pt/N-rGO and (f, g, h) PtCu (1:2)/N-rGO catalysts [33].

The electrochemical activity of the as-synthesized electrocatalysts were determined using $\mathrm{CV}$ measurements in acidic medium at a scan rate of $20 \mathrm{mV} / \mathrm{s}$ from -0.2 to $1.0 \mathrm{~V}$ as already described in case of $\mathrm{PtCo} / \mathrm{rGO}$ electrocatalysts A. Pt loading of $89 \mu \mathrm{g} / \mathrm{cm}^{2}$ calculated in $\mathrm{Pt} / \mathrm{N}-\mathrm{rGO}$ and $\mathrm{PtCu} / \mathrm{N}-\mathrm{rGO}$ electrocatalysts. A 6-times higher ECSA value for $\mathrm{PtCu}(1: 2) / \mathrm{N}$-rGO electrocatalyst $\left(85.7 \mathrm{~m}^{2} / \mathrm{g}\right)$ was found than commercial Pt/C $\left(14.3 \mathrm{~m}^{2} / \mathrm{g}\right)$ catalyst suggesting an enhanced electrochemical behavior of the as synthesized $\mathrm{PtCu} / \mathrm{N}$-rGOelectrocatalyst having a $\mathrm{PtCu}$ molar ratio of 1:2.

The total metal surface area per mass (SA) assuming the spherical shape of the nanoparticles is calculated using the following equation [124].

$$
\mathrm{SA}=6000 / \rho \mathrm{d}
$$

where $\rho$ is Pt density $\left(21.4 \mathrm{~g} / \mathrm{cm}^{2}\right)$ and $\mathrm{d}$ is the average size of Pt nanoparticles as measured by XRD and TEM ( $3 \mathrm{~nm}$ in the present case for $\mathrm{PtCu} / \mathrm{N}$-rGO electrocatalyst having a Pt:Cu molar ratio of 1:2.

The Pt utilization is related to the contact of the metal and the accessibility of the metals with the electrolyte. It is expressed by the ratio of ECSA to SA as given below [124]:

$$
\text { Pt utilization }(\%)=\text { ECSA } / \text { SA } \times 100
$$

Using this equation the \% utilization for $\mathrm{Pt}$ in $\mathrm{PtCu} / \mathrm{N}$ rGO electrocatalyst having a Pt:Cu molar ratio of 1:2 was calculated to be almost $92 \%$ and is nearly 2 - times higher to that exhibited by comm. Pt/C (52\%) based on SA of $\mathrm{Pt} / \mathrm{C}$ equal to $27 \mathrm{~m}^{2} / \mathrm{g}$ [124].

The electrochemical performance of the assynthesized $\mathrm{PtCu} / \mathrm{N}-\mathrm{rGO}$ electrocatalysts towards MOR was measured using $\mathrm{CV}$ in acidic medium and these results are shown in Fig. 21 and Fig. 22 respectively.

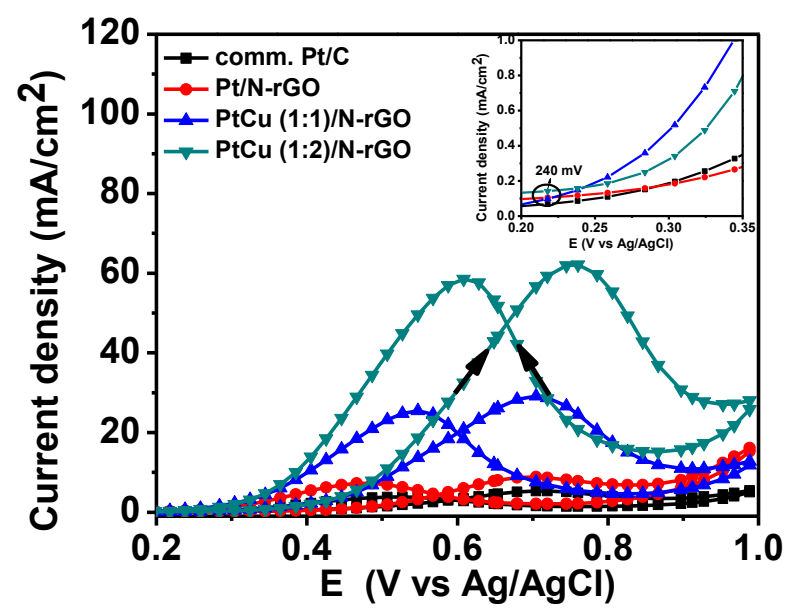

Fig. 21. Cyclic voltamograms (CV) in $1 \mathrm{M} \mathrm{H}_{2} \mathrm{SO}_{4}+2 \mathrm{M} \mathrm{CH} \mathrm{CH}_{3} \mathrm{OH}$ saturated with $\mathrm{N}_{2}$ at a scan rate of $20 \mathrm{mV} / \mathrm{s}$ using (a) commercial Pt/C (b) $\mathrm{Pt} / \mathrm{N}-\mathrm{rGO}(\mathrm{c}) \mathrm{PtCu}(1: 1) / \mathrm{N}-\mathrm{rGO}$ and (d)PtCu (1:2)/N-rGO. Right top inset represents the onset potentials the above said catalysts [33].

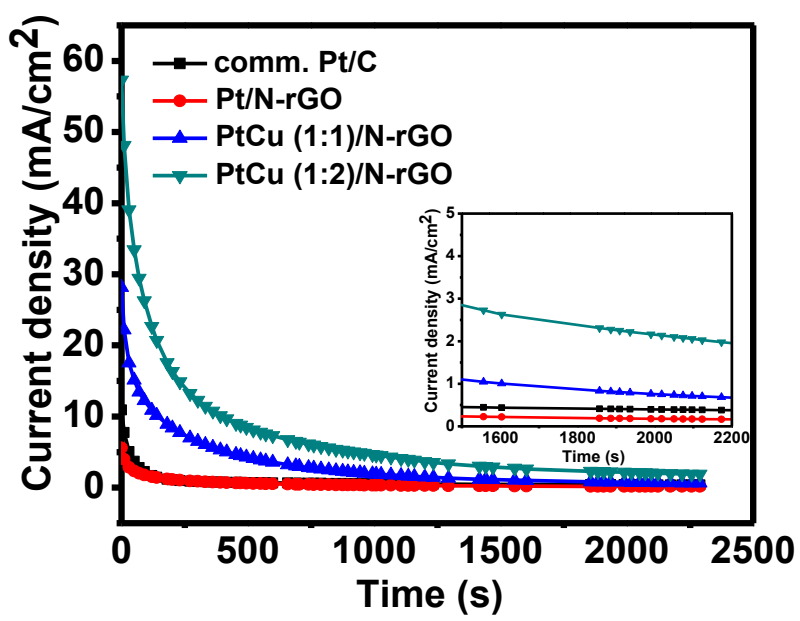

Fig. 22. Chroamperometric curves of different catalysts synthesized in the present work in $2 \mathrm{M} \mathrm{CH}_{3} \mathrm{OH}$ and $1 \mathrm{M} \mathrm{H}_{2} \mathrm{SO}_{4}$ at a potential of $0.7 \mathrm{~V}$ for 2200s [33].

From Fig. 21 it was observed that the peak forward anodic current density $\left(\mathrm{I}_{\mathrm{F}}\right)$ for MOR exhibited by using $\mathrm{PtCu}(1: 2) / \mathrm{N}-\mathrm{rGO}$ is $62.05 \mathrm{~mA} / \mathrm{cm}^{2}$ and is about 6 times higher than $\mathrm{Pt} / \mathrm{N}-\mathrm{rGO}\left(9.321 \mathrm{~mA} / \mathrm{cm}^{2}\right)$ and 11.6 times higher to those observed for commercial $\mathrm{Pt} / \mathrm{C}$ (5.346 $\left.\mathrm{mA} / \mathrm{cm}^{2}\right)$ catalysts [99]. For $\mathrm{PuCu}(1: 2) / \mathrm{N}-\mathrm{rGO}$ catalyst it is comparable to those observed for $\mathrm{PtCu}(1: 1) / \mathrm{rGO}(55.2$ $\left.\mathrm{mA} / \mathrm{cm}^{2}\right)$ [98] and $\mathrm{PtCu}(1: 1) / \mathrm{PC}-950\left(28.3 \mathrm{~mA} / \mathrm{cm}^{2}\right)$ and $\mathrm{PtCu}(1: 1) / \mathrm{PC}-950\left(23.7 \mathrm{~mA} / \mathrm{cm}^{2}\right)$ catalysts [116]. The lower $\mathrm{I}_{\mathrm{F}}$ values observed for Pt supported on $\mathrm{N}$ doped $\mathrm{rGO}$ and $\mathrm{Pt} / \mathrm{C}$ catalysts indicates that more carbonaceous species are accumulated on these electrodes and thus have lower catalytic activity towards MOR. Thus, the higher catalytic activity in $\mathrm{PtCu} / \mathrm{N}-\mathrm{rGO}$ electrocatalyst having a $\mathrm{Pt}: \mathrm{Cu}$ molar ratio of $1: 2$ is mainly attributed to the alloying $\mathrm{Pt}$ with $\mathrm{Cu}$, thus making $\mathrm{Pt}$ sites available for further MOR, thus accelerating the reaction kinetics. The onset potentials (shown in inset of Fig. 22) on $\mathrm{PtCu}$ (1:2)/N-rGO, Pt/N-rGO and comm Pt/C are found to be $0.240,0.244$ and $0.302 \mathrm{~V}$. Lower onset potential implies 


\section{Advanced Materials Letters www.vbripress.com/aml}

that methanol is easiest to oxidize on the surface of $\mathrm{PtCu}$ (1:2)/N-rGO electrocatalyst as compared to that on other catalysts. The onset potential for $\mathrm{PtCu}(1: 2) / \mathrm{N}-\mathrm{rGO}$ is 60 $\mathrm{mV}$ negatively shifted in comparison to $\mathrm{Pt} / \mathrm{C}$ showing that much lower energy is required to break the $\mathrm{C}-\mathrm{H}$ bond in methanol using the as-synthesized $\mathrm{PtCu}(1: 2) / \mathrm{N}-\mathrm{rGO}$ electrocatalyst.

From the chronoamperometric curves for different catalysts shown in Fig. 22, it is seen that all the electrocatalysts used in the present work show a rapid decay in current density for MOR during the initial stage of experiments. This degradation in current density may be attributed to the adsorption of $\mathrm{CO}$ on $\mathrm{Pt}$ active sites. However, upon long time running, a quasiequilibrium steady state of the current density is achieved. During the whole time of 2200s, the current density of $\mathrm{PtCu}(1: 2) /$ $\mathrm{N}$ - rGO electrocatalyst towards methanol electro-oxidation $\left(2.216 \mathrm{~mA} / \mathrm{cm}^{2}\right)$ was almost 6 times higher to that observed for Pt/N-rGO $\left(0.3507 \mathrm{~mA} / \mathrm{cm}^{2}\right)$ and about 10 times higher to that observed for commercially available $\mathrm{Pt} / \mathrm{C}\left(0.216 \mathrm{~mA} / \mathrm{cm}^{2}\right)$ catalysts indicating that $\mathrm{N}$ group on the rGO improves the electrochemical activity as well as the durability of the as synthesized $\mathrm{PtCu} / \mathrm{N}-\mathrm{rHO}$ electrocatalysts. Moreover, the current decayed more slowly for $\mathrm{PtCu}(1: 2) / \mathrm{N}-\mathrm{rGO}$ electrocatalyst as compared to commercial $\mathrm{Pt} / \mathrm{C}$ indicating less accumulation of $\mathrm{CO}$ on $\mathrm{Pt}$ electrode. The long-term poisoning ratio for $\mathrm{Pt} / \mathrm{C}, \mathrm{Pt} / \mathrm{N}-\mathrm{rGO}, \mathrm{PtCu}(1: 2) / \mathrm{N}-\mathrm{rGO}, \mathrm{PtCu}(1: 2) / \mathrm{N}-\mathrm{rGO}$ are $0.35,0.24,0.130,0.085 \% \mathrm{~s}^{-1}$. The lower poisoning rate of $\mathrm{PtCu}(1: 2) / \mathrm{N}-\mathrm{rGO}$ electrocatalyst in comparison to $\mathrm{Pt} / \mathrm{N}-\mathrm{rGO}$ and $\mathrm{Pt} / \mathrm{C}$ confirms its high tolerance to $\mathrm{CO}$ and other carbon intermediate species formed during MOR.

The single cell DMFC electrochemical performance of the as-synthesized $\mathrm{Pt} / \mathrm{N}-\mathrm{rGO}, \mathrm{PtCu} / \mathrm{N}-\mathrm{rGO}$ electrocatalyst having a $\mathrm{Pt}: \mathrm{Cu}$ ratio of $1: 1$ as well as $1: 2$ and commercially available $\mathrm{Pt} / \mathrm{C}$ is depicted in Fig. 23. The tests were conducted at $100{ }^{\circ} \mathrm{C}, 1$ bar using $2 \mathrm{M} \mathrm{CH}_{3} \mathrm{OH}$ solution using a $3 \mathrm{mg} / \mathrm{cm}^{2}$ catalyst loading and $20 \%$ metal on N-rGO nanosheets.

From Fig. 23 it was observed that the power density for all the electrocatalysts is almost same in the lower current discharge region $\left(\leq 100 \mathrm{~mA} / \mathrm{cm}^{2}\right)$, however in the higher current discharge region the power density for Commerical Pt/C, Pt/N-rGO, PtCu (1:1)/N-rGO and $\mathrm{PtCu}(1: 2) / \mathrm{N}-\mathrm{rGO}$ were found to be $32 \mathrm{~mW} / \mathrm{cm}^{2}$, $48 \mathrm{~mW} / \mathrm{cm}^{2}, \quad 115 \mathrm{~mW} / \mathrm{cm}^{2}$ and $152.4 \mathrm{~mW} / \mathrm{cm}^{2}$, respectively. This power density exhibited by $\mathrm{PtCu}$ (1:2)/N-rGO electrocatalyst is $\sim 3$ higher than exhibited by $\mathrm{Pt} / \mathrm{N}-\mathrm{rGO}$ and $\sim 4$ times higher than that of comm. Pt/C catalyst $\left(32 \mathrm{~mW} / \mathrm{cm}^{2}\right)$, thus confirming the higher electrochemical performance of $\mathrm{PtCu} / \mathrm{N}-\mathrm{rGO}$ electrocatalyst having a Pt:Cu molar ratio of $1: 2$ as compared those having a $\mathrm{Pt}: \mathrm{Cu}$ molar ratio of $1: 1$ and other electrocatalysts. The performance is associated with a simplified mechanism of action i.e., the oxygenated species $(\mathrm{OH})$ generated near the Pt surface helped in the removal of $\mathrm{CO}$ adsorbed on $\mathrm{Pt}$ surfaces and the $\mathrm{N}$ group of the rGO provide a strong ability to bind the metal nanoparticles with the support material leading to the enhanced electrochemical activity of $\mathrm{PtCu} / \mathrm{N}-\mathrm{rGO}$ electrocatalysts. Lower number of oxygenated species leads to the reduction of electrochemical activity of the catalysts. Thus, the combined effect of using $\mathrm{Cu}$ in $\mathrm{PtCu}$ alloy and using $\mathrm{N}$ doped $\mathrm{rGO}$ instead of pure rGO promote the electro-oxidation of methanol as well as provide the long-term stability of the electrocatalysts synthesized in the present work.

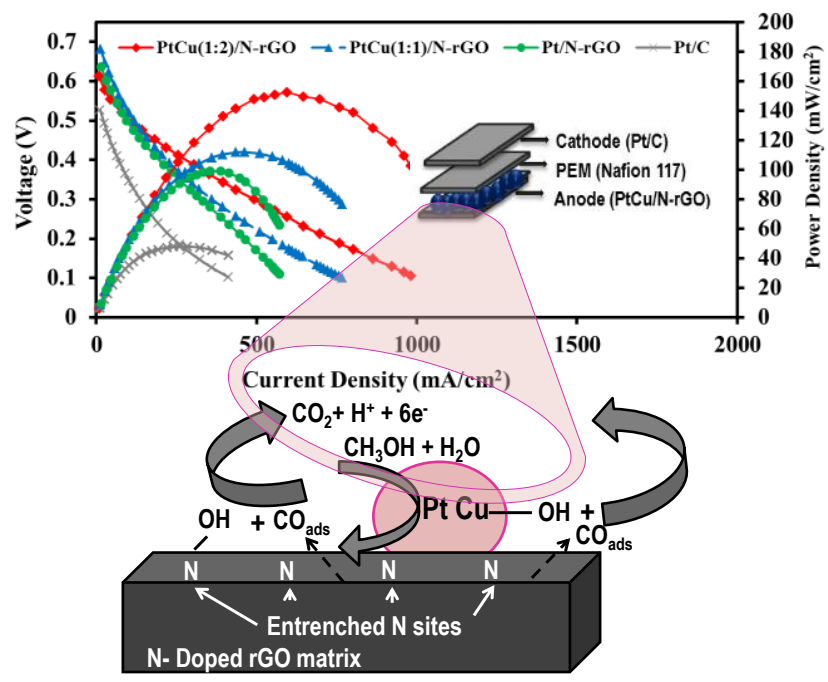

Fig. 23. Single cell performance of a DMFC having an area of $5 \mathrm{~cm}^{2}$ showing the cell voltage-current density and power density at $100{ }^{\circ} \mathrm{C}$ using comm. Pt/C, Pt/N-rGO,PtCu/N-rGO anode electrocatalysts having a Pt:Cu molar ratio of $1: 1$ and $1: 2$. At the anode $2 \mathrm{M}$ methanol flow rate of $200 \mathrm{sccm}$ and $1 \mathrm{bar}$ pressure was used and at the cathode the $P_{\mathrm{O} 2}=1.5$ bar and $\mathrm{O}_{2}$ flow rate of $200 \mathrm{sccm}$ was used. The anode and the cathode electrodes were separated by a Nafion 117 membrane [33]

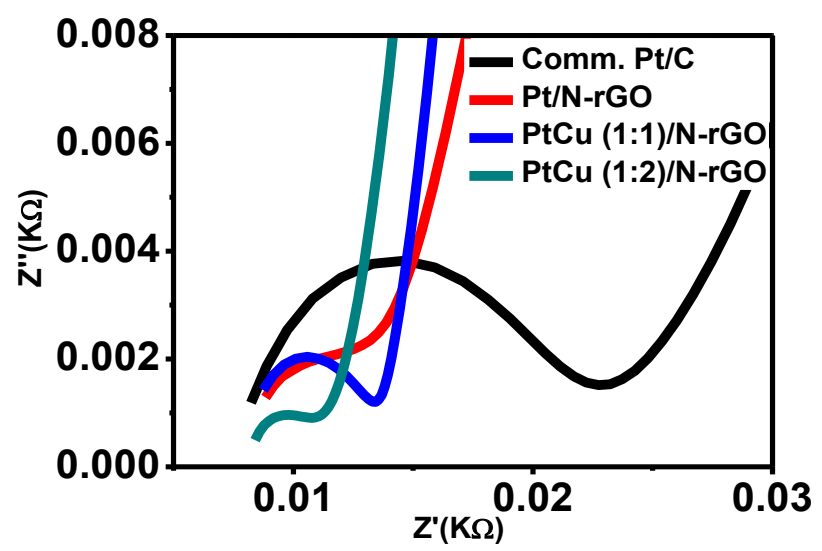

Fig. 24. Nyquist plots of Commercial Pt/C, Pt/N-rGO, PtCu(1:1)/N-rGO and $\mathrm{PtCu}(1: 2) / \mathrm{N}-\mathrm{rGO}$ catalysts [33].

The electrochemical activity of the as-synthesized electrocatalysts were further confirmed by Electrochemical Impedance Spectroscopy (EIS) for various electrocatalysts synthesized in the present work and the results these measurements are shows as Nyquist plots shown in Fig. 24 for MOR using $1 \mathrm{M} \mathrm{H}_{2} \mathrm{SO}_{4}$ and $2 \mathrm{M}$ $\mathrm{CH}_{3} \mathrm{OH}$ at $0.2 \mathrm{~V}$ vs $\mathrm{Ag} / \mathrm{AgCl}$. It is seen that these plots are 


\section{Advanced Materials Letters www.vbripress.com/aml}

composed of two parts, one semicircle and one straight line as also observed for PtCo/rGO electrocatalysts. The semicircle in the high frequency region is related to charge transfer process occurring at the electrode/electrolyte interface, the straight line in the low frequency region can be due to Warburg impedance [120]. The following equation was used to calculate the $\mathrm{R}_{\mathrm{CT}}$ in each case:

$$
\mathrm{K}_{\mathrm{app}}=\frac{\mathrm{RT}}{\mathrm{n}^{2} \mathrm{ACR} \mathrm{CT}^{2}}
$$

where $\mathrm{n}$ is number of electrons transferred, $\mathrm{F}$ is Faraday's constant, $\mathrm{R}$ is rate constant, $\mathrm{T}$ is temperature, $\mathrm{A}$ is area of the electrode and $\mathrm{R}_{\mathrm{CT}}$ was obtained from the fitted Nyquist plots, $\mathrm{C}$ is concentration of electrolyte.

The resistance to charge transfer $\left(\mathrm{R}_{\mathrm{CT}}\right)$ values for $\mathrm{Pt} / \mathrm{C}, \mathrm{Pt} / \mathrm{N}-\mathrm{rGO}, \mathrm{PtCu}(1: 1) / \mathrm{N}-\mathrm{rGO}$ and $\mathrm{PtCu}(1: 2) / \mathrm{N}-\mathrm{rGO}$ catalysts were calculated to be $26.19,16.72,4.478$ and $3.676 \Omega / \mathrm{cm}^{2}$ respectively thus demonstrating the better electrochemical performance of $\mathrm{PtCu} / \mathrm{N}-\mathrm{rGO}$ electrocatalyst having a $\mathrm{Pt}: \mathrm{Cu}$ molar ratio of $1: 2$ as compared to other catalysts due to least $\mathrm{R}_{\mathrm{CT}}$ value. This is mainly due to the alloying of $\mathrm{Cu}$ with $\mathrm{Pt}$ and the $\mathrm{N}$ group of $\mathrm{rGO}$ which helps in the less poisoning of the electrode, thus exhibits better charge transfer rate.

The superior performance exhibited by $\mathrm{PtCu}(1: 2) / \mathrm{N}-$ rGO anode electrocatalyst in the present work is mainly due to two reasons : (i) $\mathrm{N}$ group in $\mathrm{N}-\mathrm{rGO}$ support material acts as a growth and nucleation site for the formation of uniformly dispersed $\mathrm{PtCu}$ nanoparticles (ii) electrochemical performance of $\mathrm{PtCu}$ alloy nanoparticles in which the incorporation of copper into the lattice of platinum lowered not only the onset potential for MOR but also lowered the overall activation energy of the reaction. As mentioned earlier, the $\mathrm{N}$ group in the $\mathrm{N}$-rGO not only helps in the homogenous dispersion of $\mathrm{PtCu}$ nanoparticles on the N-rGO support but also minimize their agglomeration by stabilizing them on it $[\mathbf{1 5 , 2 7 ]}$. Further the nitrogen doping enhances the particle nucleation which is attributed to the physical surface defects as Pt phase nucleation preferentially occurs in regions of defective or amorphous type carbon. The incorporation of nitrogen into carbon leads to the reduction of surface oxygen group and increased stability towards oxidation. Further nitrogen alters the electron donating character of the support which impacts the binding of support to the catalyst. Also, nitrogen incorporates asymmetry in spin density on N-rGO network that facilitates the charge transfer from the carbon support to the adsorbing oxygen molecule and results in the formation of superoxide ion $\left(\mathrm{O}^{-2}\right)$. This weakens the $\mathrm{O}-\mathrm{O}$ bond promotes its dissociation, thereby enhancing the MOR activity. The higher electrochemical activity of the $\mathrm{PtCu}(1: 2) / \mathrm{N}-\mathrm{rGO}$ electrocatalyst in comparison to $\mathrm{Pt} / \mathrm{C}$ clearly demonstrate the importance of nitrogen in N-rGO nanosheets. In case of $\mathrm{Pt} / \mathrm{C}$ catalyst there are no oxygenated species, and thus the oxidation of $\mathrm{CO}_{\text {ads }}$ is known to follow the less efficient Langmuir-Hinshelwood (LH) mechanism. Further, a high over-potential is required in case pf $\mathrm{Pt} / \mathrm{C}$ catalyst for the formation of oxygenated species specially $\mathrm{OH}$ as compated to $\mathrm{PtCu} / \mathrm{N}-\mathrm{rGO}$ electrocatalysts by the activation of water on the $\mathrm{Pt}$ surface. Thus, although $\mathrm{Cu}$ nanoparticles alone do not have any catalytic action towards the oxidation of methanol, however, when alloying with $\mathrm{Pt}$ to form $\mathrm{PtCu}$ alloy, they modify its electronic properties and then promote the MOR efficiently as explained by the following equations:

$$
\mathrm{Cu}+\mathrm{H}_{2} \mathrm{O} \rightarrow \mathrm{Cu}-\mathrm{OH}_{\mathrm{ads}}+\mathrm{H}^{+}+\mathrm{e}
$$

It is well known that $\mathrm{CO}$ poisoneous species are generally generated near the active $\mathrm{Pt}$ sites during the oxidation of methanol, thus its surface gets deterioted and the methanol oxidation does not take place efficiently.

$$
\begin{aligned}
& \mathrm{Pt}+\mathrm{CH}_{3} \mathrm{OH} \rightarrow \mathrm{Pt}\left(\mathrm{CH}_{3} \mathrm{OH}\right)_{\mathrm{ads}} \\
& \mathrm{Pt}\left(\mathrm{CH}_{3} \mathrm{OH}\right)_{\mathrm{ads}} \rightarrow \mathrm{Pt}-(\mathrm{CO})_{\mathrm{ads}}+4 \mathrm{H}^{+}+4 \mathrm{e}
\end{aligned}
$$

Then, $\mathrm{OH}$ species adsorbed by the second metal $(\mathrm{Cu})$ reacts with the $\mathrm{CO}$ or other $\mathrm{C}$ intermediate species absorbed on $\mathrm{Pt}$ surface and convert them into $\mathrm{CO}_{2}$ as shown in the following equation:

$$
\mathrm{Pt}-(\mathrm{CO})_{\mathrm{ads}}+\mathrm{Cu}-\mathrm{OH}_{\mathrm{ads}} \rightarrow \mathrm{Pt}+\mathrm{Cu}+\mathrm{CO}_{2}+\mathrm{H}^{+}+\mathrm{e}^{-}
$$

Therefore, with the addition of $\mathrm{Cu}$ in $\mathrm{Pt}$, more $\mathrm{OH}$ species are formed during water activation which helps in oxidizing CO-like intermediates on $\mathrm{PtCu} / \mathrm{N}-\mathrm{rGO}$ catalyst surface to $\mathrm{CO}_{2}$ more easily in comparison to other catalysts. Alloying $\mathrm{Pt}$ with $\mathrm{Cu}$ in case of $\mathrm{PtCu} / \mathrm{N}-\mathrm{rGO}$ electrocatalysts decreases th Pt-Pt interatomic distance, increases the $\mathrm{Pt}$ d-band vacancy thus promoting the breaking of $\mathrm{O}-\mathrm{O}$ bond in addition to change the electronic structure of Pt. All these factors in $\mathrm{PtCu} / \mathrm{N}-\mathrm{rGO}$ electrocatalysts are responsible for the lower coverage of $\mathrm{CO}$ on the Pt surfaces and thus more active Pt sites are created regularly for MOR: hence faster reaction kinetics are exhibited by these electrocatalysts as compared to $\mathrm{Pt} / \mathrm{C}$ or $\mathrm{Pt} / \mathrm{N}$-rGO electrocatalysts.

In summary, the as-synthesized $\mathrm{PtCu}(1: 2) / \mathrm{N}-\mathrm{rGO}$ electrocatalyst of size $3 \mathrm{~nm}$ was found to exhibit much higher electrochemical activity as compared to other combinations of $\mathrm{Pt}$ and $\mathrm{Cu}$ for MOR in acidic medium. It is cheap, highly efficient and stable electrocatalyst for MOR in which $\mathrm{PtCu}$ alloy nanoparticles are homogeneously dispersed on the surface of $\mathrm{N}$ doped rGO nanosheets. The power density of the as-synthesized $\mathrm{PtCu} / \mathrm{N}-\mathrm{rGO}$ electrocatalyst having a $\mathrm{Pt}: \mathrm{Cu}$ molar ratio of $1: 2$ was nearly 3 times higher than $\mathrm{Pt}$ supported on $\mathrm{N}$ doped $\mathrm{rGO}$ and 4 times higher than $\mathrm{Pt} / \mathrm{C}$ catalyst. The higher current density values obtained for this electrocatalyst indicates that this electrode has a better $\mathrm{CO}$ resistance than $\mathrm{Pt} / \mathrm{N}-\mathrm{rGO}$ and commercial $\mathrm{Pt} / \mathrm{C}$ catalysts. The oxophilic nature of $\mathrm{Cu}$ atoms not only modify the electronic structure of $\mathrm{Pt}$ by bi-functional mechanism but also minimize the accumulation of $\mathrm{OH}$ and $\mathrm{CO}$-like species on Pt surface thereby creating fresh active Pt sites for efficient MOR. The $\mathrm{N}$-groups on rGO not only help in decreasing the agglomeration among rGO nanosheets but also provide additional anchoring sites between $\mathrm{PtCu}$ nanoparticles and rGO by a strong interfacial bonding, 


\section{Advanced Materials Letters www.vbripress.com/aml}

thereby increasing its stability and durability. In brief, the as-synthesized $\mathrm{PtCu}(1: 2) / \mathrm{N}-\mathrm{rGO}$ catalyst has great application in a DMFC as an anode material for efficient MOR as it is relatively much cheaper and exhibits excellent electrochemical performance towards MOR as compared to commercial $\mathrm{Pt} / \mathrm{C}$ catalyst. Some of comparisons of work on MOR using PtCu nanoparticles supported on various support materials are shown in Table 4.

Table 4. Comparison of electrochemical properties of $\mathrm{PtCu}$ catalysts supported on various carbon materials as reported in the literature.

\begin{tabular}{|c|c|c|c|c|c|}
\hline $\begin{array}{l}\text { Electro- } \\
\text { catalyst }\end{array}$ & $\begin{array}{l}\text { ECSA } \\
\left(\mathrm{m}^{2} / \mathrm{g}\right)\end{array}$ & $\begin{array}{c}\text { Onset } \\
\text { potential } \\
\text { (V) }\end{array}$ & $\begin{array}{c}\text { Current } \\
\text { density } \\
\left(\mathrm{mA} / \mathrm{cm}^{2}\right)\end{array}$ & $\begin{array}{c}\text { Power } \\
\text { density } \\
\left(\mathrm{mW} / \mathrm{cm}^{2}\right)\end{array}$ & $\begin{array}{c}\text { Re- } \\
\text { ference }\end{array}$ \\
\hline $\mathrm{PtCu} / \mathrm{C}$ & 14.8 & 0.405 & $\begin{array}{c}24.6 \\
\mathrm{~mA} \mathrm{~cm}{ }^{2}\end{array}$ & ---- & 99 \\
\hline $\mathbf{P t} / \mathbf{C}$ & 38.87 & 0.302 & $5.6 \mathrm{~mA} / \mathrm{cm}^{2}$ & -- & 99 \\
\hline $\begin{array}{l}\mathrm{PtCu} / \mathrm{PC}- \\
950\end{array}$ & 63.2 & 0.941 & $28.3 \mathrm{~mA} / \mathrm{cm}^{2}$ & --- & 116 \\
\hline $\begin{array}{l}\mathrm{Pt}_{50} \mathrm{Cu}_{50} / \\
\text { rGO }\end{array}$ & 63.3 & --- & $55.2 \mathrm{~mA} / \mathrm{cm}^{2}$ & -- & 98 \\
\hline $\begin{array}{l}\mathrm{PtCu}_{2} / \\
\text { rGO }\end{array}$ & 31.7 & 0.423 & $642 \mathrm{~mA} / \mathrm{mg}$ & & 96 \\
\hline $\begin{array}{l}\mathrm{PtCu} / 3 \mathrm{D} \\
\text { N-rGO }\end{array}$ & 39.5 & 0.38 & $741.2 \mathrm{~mA} / \mathrm{mg}_{\mathrm{Pt}}$ & ---- & 125 \\
\hline $\begin{array}{l}\mathrm{PtCu} / \\
\text { rGO }\end{array}$ & --- & 0.40 & $542.7 \mathrm{~mA} / \mathrm{mg}_{\mathrm{pt}}$ & -- & 125 \\
\hline $\begin{array}{l}\mathrm{PtCu} / \\
\mathrm{XC}-72\end{array}$ & --- & 0.42 & $362.7 \mathrm{~mA} / \mathrm{mg}_{\mathrm{Pt}}$ & -- & 125 \\
\hline $\begin{array}{l}\mathrm{PtCu} / \\
\text { NrGO }\end{array}$ & & ---- & $\begin{array}{c}0.916 \\
\mathrm{~A} / \mathrm{mg}_{\mathrm{Pt}}\end{array}$ & ---- & 126 \\
\hline $\begin{array}{l}\text { PtRu / } \\
\text { N-rGO }\end{array}$ & ----- & 0.44 & ---- & $93 \mathrm{~mW} / \mathrm{cm}^{2}$ & 123 \\
\hline $\begin{array}{l}\operatorname{PtCu}(1: 2) \\
/ \mathrm{N}-\mathrm{rGO}\end{array}$ & 85.7 & 0.240 & $62.05 \mathrm{~mA} / \mathrm{cm}^{2}$ & $\begin{array}{c}152.4 \\
\mathrm{~mW} / \mathrm{cm}^{2}\end{array}$ & $\begin{array}{c}\text { (present } \\
\text { work) } 33\end{array}$ \\
\hline
\end{tabular}

Methanol electro-oxidation using a hybrid of multiwalled carbon nanotubes and reduced graphene oxide

In the above sections methanol electro-oxidation has been studied using Pt and Pt based nanoparticles supported on a number of carbon materials including carbon black, multiwalled carbon nanotubes (CNTs), reduced graphene oxide (rGO) and N-doped rGO etc. Out of all these support materials rGO or N-doped rGO has been preferred over other materials because of its large surface area, high thermal conductivity $(\sim 5000 \mathrm{~W} / \mathrm{mK})$ and high mobility of charge carriers $\left(200,000 \mathrm{~cm}^{2} / \mathrm{Vs}\right)$. However, one the major problems in using $\mathrm{rGO}$ is its agglomeration in solutions due to $\pi-\pi$ interaction between the individual nanosheets, thus making the surface area much lower in addition to lower conductivity and other mechanical properties [127]. Therefore, efforts are being made in the recent years to reduce this interaction between graphene nanosheets by introducing some other conducting material in order to use the unique properties of graphene. Although a lot of research work was carried out using the above-mentioned support materials for $\mathrm{Pt}$ and $\mathrm{Pt}$ based bi-metallic or tri- metallic nanomaterials, the research on the use of hybrid materials is limited [122,132-134]. Very recently $\mathrm{CuPt}$ alloy nanoparticles assembled on rGO, Vulcan XC-72 (VC) and their hybrid (rGO-VC) were studied by Yilmaz et. al. [118] for fuel cell reactions and it is reported that using $\mathrm{Cu}_{45} \mathrm{Pt}_{55} / \mathrm{rGO}-\mathrm{VC}$ hybrid electrocatalyst exhibited high catalytic activity and a power density of $480 \mathrm{~mW} / \mathrm{cm}^{2}$ in a PEMFC. Pongpichayakul et. al. [128] has used a hybrid of rGO and CNTs as a support material for $\mathrm{Pt}$ nanoparticles and reported a anodic current density of 350 $\mathrm{mA} / \mathrm{mg}_{\mathrm{Pt}}$. Wang et. al. [129] has studied MOR using Pt$\mathrm{Ru} / \mathrm{rGO}-\mathrm{CNTs}$ for MOR. Yan et. al. [130] has obtained a mass activity of $0.8 \mathrm{~A} / \mathrm{mg}$ for MOR using Pt/CNTs-N doped graphene support, which is much higher to that observed for commercial $\mathrm{Pt} / \mathrm{C}(0.2 \mathrm{~A} / \mathrm{mg})$. In our study we have used a hybrid of rGO and CNTs for anchoring $\mathrm{Pt}$ nanoparticles $(2-3 \mathrm{~nm})$ for the electro-oxidation of methanol in acidic medium [46]. Some important results of our investigations on $\mathrm{Pt} / \mathrm{rGO}-\mathrm{CNTs}$ are described in this section.

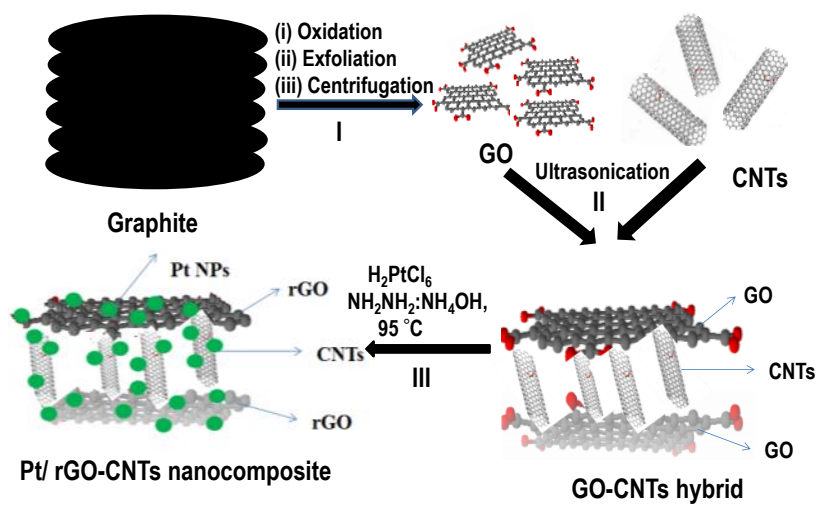

Fig. 25. Schematic diagram showing the preparation of $\mathrm{Pt} / \mathrm{rGO}-\mathrm{CNT}$ nanocomposites [46].

Pt nanoparticles supported on a hybrid of rGO and CNTs were prepared in accordance to the method as reported by Woo et. al. [95] via the in-situ chemical reduction of exfoliated GO and chloroplatinic acid hexahydrate in the presence of acid functionalized CNTs (2:1 wt ratio) in a mixture of hydrazine hydrate and $\mathrm{NH}_{4} \mathrm{OH}$ solution at $95{ }^{\circ} \mathrm{C}$ for $1 \mathrm{~h}$ in an oil bath. The $\mathrm{pH}$ of the solution was maintained constant at 11 by adding $1 \mathrm{M}$ $\mathrm{NaOH}$. The schematic diagram for the preparation of $\mathrm{Pt} / \mathrm{rGO}-\mathrm{CNTs}$ in the present work is shown in Fig. 25.

As in case of $\mathrm{PtCo} / \mathrm{rGO}$ or $\mathrm{N}-\mathrm{rGO}$ electrocatalysts, the as-synthesized $\mathrm{Pt} / \mathrm{rGO}-\mathrm{CNTs}$ catalyst was also characterized by a number of techniques including XRD, UV-Vis spectroscopy, Raman spectroscopy etc. The electrochemical measurements were carried out using CV. Fig. 26(a) shows a typical XRD pattern for Pt/rGO-CNTs nanocomposites synthesized in the present work. The diffraction peak at $2 \theta=25.57^{\circ}$ corresponds to the (002) plane of graphitized carbon. After chemical reduction using a mixture of hydrazine hydrate and ammonium hydroxide, the diffraction pattern observed for GO $\left(2 \theta=11.24^{\circ}\right)$ was disappeared and a broader (002) 


\section{Advanced Materials Letters www.vbripress.com/aml}

diffraction peak at $2 \theta=25.57^{\circ}$ was observed. It clearly indicates the removal of oxygen-containing functional groups and water molecules and formation of ordered graphene. Also, the broadening of (002) diffraction peak indicates the smaller size of graphene compared to the original graphite powder and GO. The other diffraction peaks observed at $2 \theta$ values of $39.68,46.24$ and $81.28^{\circ}$ can be attributed to (111), (200) and (311) planes, respectively of face-centered-cubic crystallographic structure of Pt [JCPDS 4-802]. From this figure it is seen that there is a small change in the position of $\mathrm{C}(002)$ diffraction peak for rGO/CNTs hybrid than those observed for graphene.
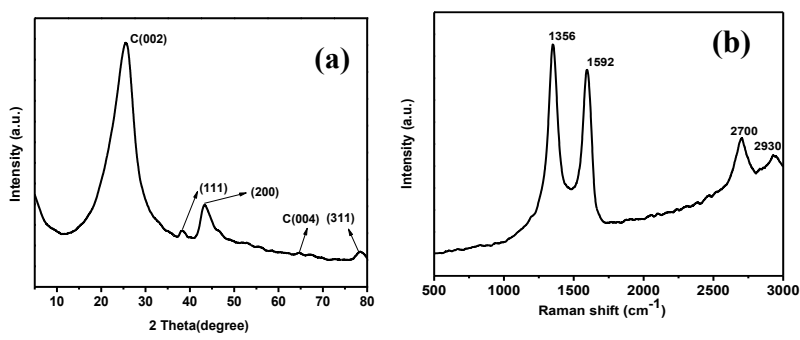

Fig. 26. (a) XRD pattern (b) Raman spectra of Pt/rGO-CNTs [46].

The slight shift in $2 \theta$ values observed for $\mathrm{rGO} / \mathrm{CNTs}$ hybrid in the XRD pattern indicates the formation of a strong interaction between rGO and CNTs. The incorporation of CNTs causes the development of some stresses in the rGO nanosheets and causes a shift in $2 \theta$ value. The bonding between $\mathrm{Pt}$ and rGO/CNTs was not a weak physical bond but a strong chemical bond. The diffraction peak for $\mathrm{Pt}(200)$ was used to estimate the average Pt particle size using the Scherrer's equation: $\mathrm{D}=0.89 \lambda / \beta \operatorname{Cos} \theta$. Here the wavelength $\lambda$ is equal to $0.15418 \mathrm{~nm}$ and $\beta$ is the full width at half-maximum (FWHM). The calculated average particle size of $\mathrm{Pt}$ nanoparticles on graphene/CNTs hybrid composite was found to be $\sim 5 \mathrm{~nm}$.

Fig. 26(b) shows a typical Raman spectrum of $\mathrm{Pt} / \mathrm{rGO}-\mathrm{CNT}$ s electrocatalyst synthesized in the present work. The G-band observed at $1592 \mathrm{~cm}^{-1}$ was mainly due to $\mathrm{sp}^{2}$ hybridized carbon atoms and D-band at1356 $\mathrm{cm}^{-1}$ was due to the defects present. The G-band of pure graphite is mainly observed at $1580 \mathrm{~cm}^{-1}$, so the shifting in the frequency of $12 \mathrm{~cm}^{-1}$ in the rightward direction may be due to the reduction in size of the in-plane $\mathrm{sp}^{2}$ domains possibly due to strong oxidation. It is also likely that the presence of isolated double bonds in $\mathrm{rGO} / \mathrm{CNT}$ hybrid resonate at frequencies higher than that of the G-band of graphite [135]. The ID/IG ratio for graphene is 1.09 whereas the ID/IG ratio rGO-CNTs hybrid composite is increased to 1.166 (Fig. 26(b)) and is due to more defects introduced. The shift and shape of the overtone of the D-band, called 2D band around $2700 \mathrm{~cm}^{-1}$ can be correlated to the number of graphene layers. Weak and broad 2D peak is the indication of disorder. A defect activated peak, called the $(D+G)$ band is also observed near $2930 \mathrm{~cm}^{-1}$ in the Raman spectrum.
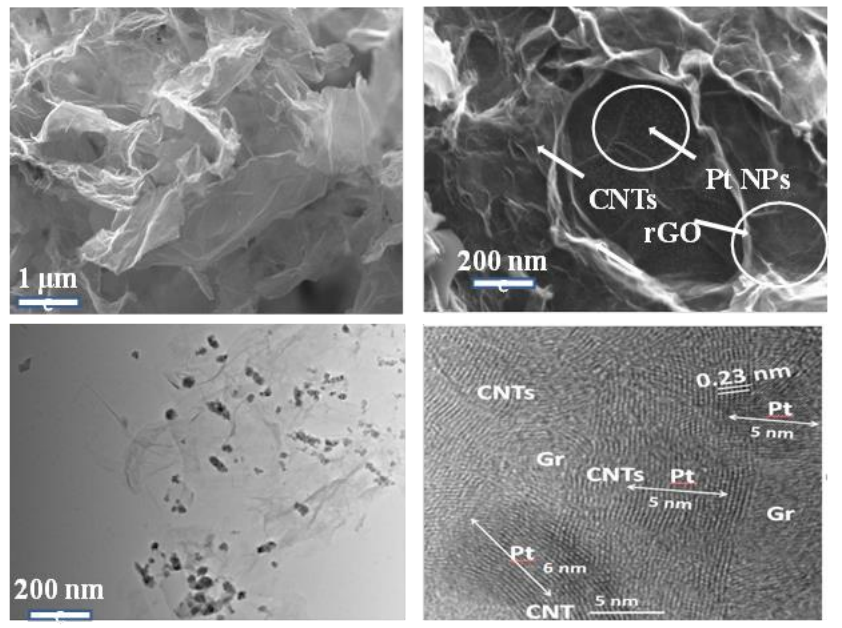

Fig. 27. SEM images of (a) rGO (b) Pt-rGO/CNT catalyst (c) TEM (d) HR TEM images Pt-rGO/CNT catalyst [46].

Fig. 27(a) and (b) shows a typical SEM micrograph of GO and Pt/rGO-CNTs nanocomposites synthesized in the present work. In the SEM micrograph shown in Fig. 27(a) the graphene nanosheets form randomly aggregated thin sheets. Fig. 27(b) shows a typical SEM image of $\mathrm{Pt} / \mathrm{rGO}-\mathrm{CNTs}$ composite in which the grphene nanosheets of wrinkled morphology forms a homogeneous network between CNTs. Pt nanoparticles are seen uniformly dispersed on $\mathrm{rGO} / \mathrm{CNTs}$ hybrid. These wrinkles prevent the aggregation of graphene nanosheets due to van der Waals forces during drying and maintaining high surface area [136]. Thus, the CNTs not only prevent the aggregation of graphene nanosheets but also increases the distance between graphene layers, thereby altering the array of graphene sheets. Fig. 27(c) shows a typical TEM image of $\mathrm{Pt} / \mathrm{rGO}-\mathrm{CNTs}$ composite. Pt nanoparticles are deposited on $\mathrm{CNT} / \mathrm{rGO}$ hybrid with almost uniform dispersion. In the HR-TEM image shown in Fig. 27(d) it is seen that most voids within CNTs network are covered with graphene nanosheets. The d-spacing value of $0.23 \mathrm{~nm}$ is due to fcc Pt (111). The average size of Pt nanoparticles estimated from TEM images are $\sim 5 \mathrm{~nm}$ on $\mathrm{CNT} / \mathrm{rGO}$ hybrid and is in agreement with XRD results. Fig. 28 shows the electrochemical measurements on $\mathrm{Pt} / \mathrm{rGO}$ CNTs catalyst.
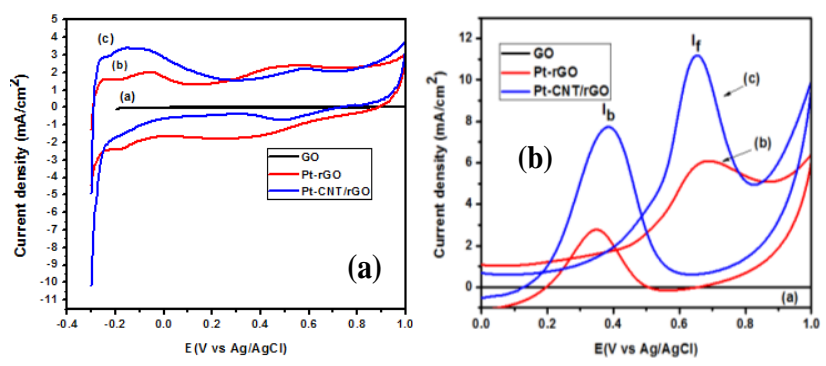

Fig. 28. Cyclic voltamograms in (a) $1 \mathrm{M} \mathrm{H}_{2} \mathrm{SO}_{4}$ solution at a scan rate of $70 \mathrm{mV} / \mathrm{s}$ (a) GO (b) Pt-/rGO and (c) Pt/rGO-CNT catalysts and (b) methanol electro-oxidation curves in $1 \mathrm{M} \mathrm{H}_{2} \mathrm{SO}_{4}$ and $2 \mathrm{M} \mathrm{CH}_{3} \mathrm{OH}$ solution at a scan rate of $70 \mathrm{mV} / \mathrm{s}$ (a) GCE (b) Pt-rGO and (c) Pt/rGO-CNT catalysts $[\mathbf{4 6}]$. 


\section{Advanced Materials Letters www.vbripress.com/aml}

Using the equation and Fig. 28(a) for the calculation of electrochemical surface area, the ECSA of Pt in $\mathrm{Pt} / \mathrm{rGO}-\mathrm{CNTs}\left(65.89 \mathrm{~m}^{2} / \mathrm{g}\right)$ was found to be much higher than that of $\mathrm{Pt} / \mathrm{rGO}$ catalyst $\left(31.79 \mathrm{~m}^{2} / \mathrm{g}\right)$, clearly demonstrating that $\mathrm{Pt} / \mathrm{rGO}-\mathrm{CNTs}$ exhibits much higher electrochemical activity than $\mathrm{Pt} / \mathrm{rGO}$ catalyst. The electrochemical activities of GO, Pt/rGO-CNTs and $\mathrm{Pt} / \mathrm{rGO}$ catalysts towards methanol electro-oxidation were evaluated using $\mathrm{CV}$ in a solution containing $2 \mathrm{M} \mathrm{CH}_{3} \mathrm{OH}$ and $1 \mathrm{M} \mathrm{H}_{2} \mathrm{SO}_{4}$ with a scan rate of $70 \mathrm{mV} / \mathrm{s}$ between $-0.2 \mathrm{~V}$ to $1.0 \mathrm{~V}$ vs $\mathrm{Ag} / \mathrm{AgCl}$ at room temperature. The $\mathrm{CV}$ curves for both electro catalysts for methanol electrooxidation are shown in Fig. 28(b). The CV curves for both the electrocatalysts show similar methanol electrooxidation anodic current peak in the forward scan $\left(\mathrm{I}_{\mathrm{f}}\right)$ and an oxidation peak in the backward scan $\left(\mathrm{I}_{\mathrm{b}}\right)$ corresponding to the removal of residual carbonaceous intermediates formed in the forward scan. It can be seen that the forward current density of Pt/rGO-CNTs catalyst $\left(11.74 \mathrm{~mA} / \mathrm{cm}^{2}\right)$ is much higher than that of $\mathrm{Pt} / \mathrm{rGO}$ catalyst $\left(6.2 \mathrm{~mA} / \mathrm{cm}^{2}\right)$. Further, the oxidation potential of methanol oxidation observed for $\mathrm{Pt} / \mathrm{rGO} / \mathrm{CNTs}$ electrocatalyst was lower $(0.65 \mathrm{~V})$ as compared with that observed for $\mathrm{Pt} / \mathrm{rGO}$ electrocatalyst $(0.68 \mathrm{~V})$. This observation again suggests that the incorporation of CNTs in rGO decreases the barrier to methanol electro-oxidation, and thus, Pt/rGOCNTs electrocatalysts performs better than $\mathrm{Pt} / \mathrm{rGO}$ catalyst and is in consistent with the ECSA results. A very small current density was observed for pure GO electrode in comparison with other catalyst as shown by a straight line in Fig. 28(b) The electrochemical stability of Pt/rGO and Pt/rGO-CNTs electrocatalysts for methanol electrooxidation was further measured by means of chronoamperometry in $2 \mathrm{M} \mathrm{CH} \mathrm{CH}_{3} \mathrm{OH}$ and $1 \mathrm{M} \mathrm{H}_{2} \mathrm{SO}_{4}$ solution at a constant potential of $0.6 \mathrm{~V}$ at a scan rate of 70 $\mathrm{mV} / \mathrm{s}$. These measurements have also shown that the electrochemical stability of Pt/rGO-CNTs electro- catalyst is much higher than that observed for $\mathrm{Pt} / \mathrm{rGO}$ electrocatalyst as the residual current density in case of $\mathrm{Pt} / \mathrm{rGO}-\mathrm{CNTs}$ electrocatalyst is much higher to that exhibited by $\mathrm{Pt} / \mathrm{rGO}$ electrocatalyst.

On the basis of above experimental results it is demonstrated that Pt/rGO-CNTs has better electrochemical activity and long term stability than commercially available $\mathrm{Pt} / \mathrm{rGO}$ catalyst presumably due to i) larger ECSA values of Pt/rGO-CNTs ii) high dispersion of Pt nanoparticles and iii) low agglomeration of graphene nanosheets in $\mathrm{rGO} / \mathrm{CNTs}$ hybrid by the incorporation of CNTs between graphene layers, thereby, reducing significantly the $\pi-\pi$ interaction.

In summary, we have demonstrated a facile synthesis of a Pt/rGO-CNTs electrocatalyst by a simultaneous chemical reduction process using a mixture of hydrazine hydrate and ammonium hydroxide as the reducing agents. Using this method, the CNTs are incorporated between the graphene nanosheets, thereby preventing their aggregation. The three-dimensional graphene-CNTs hybrid comprises a network with ultrathin graphene sheets between the CNTs bundles as revealed by SEM characterization. This electrocatalyst was found to possess much better electrochemical activity, larger ECSA values and electrochemical stability than those observed for $\mathrm{Pt} / \mathrm{rGO}$ catalyst presumably because of non-agglomeration of rGO nanosheets in rGO-CNTs hybrid as compared to that observed in pure CNTs or rGO. The results show that $\mathrm{Pt} / \mathrm{rGO}-\mathrm{CNTs}$ catalyst could be used as a promising anode material for a direct methanol fuel cell and may find applications in the fabrication of many devices such as sensors, batteries and super capacitors.

\section{Conclusions and future prospectives}

In summary, we have studied the electro-oxidation of methanol using various anode electrocatalysts in which $\mathrm{Pt}$ and $\mathrm{Pt}$ based alloy nanoparticles specially $\mathrm{PtCo}$ and $\mathrm{PtCu}$ is different molar ratio were supported them on rGO, NrGO and a hybrid of rGO and CNTs. The MOR was studied mainly in acidic medium and from a detailed studied it was observed that the electrochemical activity of these electrocatalysts were superior by many folds to that observed for commercial $\mathrm{Pt} / \mathrm{C}$ catalyst. In the bimetallic catalysts (PtCo and $\mathrm{PtCu}$ ) the enhancement of electrochemical behavior was mainly due to the alloying of Pt with the second metal $(\mathrm{Co}, \mathrm{Cu})$ which not only modifiy the electronic structure of $\mathrm{Pt}$ but also produces more $\mathrm{OH}$ species near the active sites of $\mathrm{Pt}$, thus minimizing the adsorption of $\mathrm{CO}$ and other carbonaceous specties on $\mathrm{Pt}$ surface aprt from their homogeneous dispersion of the support materials. The use of $\mathrm{N}$ group of $\mathrm{N}-\mathrm{rGO}$ in $\mathrm{PtCu} / \mathrm{N}-\mathrm{rGO}$ catalysts further improves the electrochemical stability mainly due to metal-supportinteraction. Further, in the hybrid of rGO and CNTs used as a support for $\mathrm{Pt}$ nanoparticles we have reduce significantly the $\pi-\pi$ interaction between the individual graphene nanosheets thus removing their agglomeration in solution and utilize its optimum properties.

Although during the last few years there has been a considerable improvement in the design and synthesis of a efficient and electrochemical stable catalyst for the enhancement of MOR in a DMFC through better dispersion and control of the composition of $\mathrm{Pt}$ nanoparticles with other 3-d transition metals and other, yet several parameters are still to be optimized for the commercialization of DMFCs. The present level of technology requires relatively high temperatures $\left(>100^{\circ} \mathrm{C}\right)$ and pressures before practical cell power cell densities can be achieved. Most groups working on DMFC uses high Pt loading (upto $4 \mathrm{mg} / \mathrm{cm}^{2}$ ) on the anode to increase the material to a useful rate. This level of catalyst is too high for transportation applications and it clearly indicates that the anode catalyst activity has still to be increased, perhaps by a factor by at least 10 , to reduce the noble metal loading to more acceptable level of below 0.5 $\mathrm{mg} / \mathrm{cm}^{2}$. Thus, the optimization of the electrode structure, leading to higher catalyst utilization will also contribute to increased cell performance. Methanol cross-over from anode to the cathode appears to be a major limitation at 


\section{Advanced Materials Letters www.vbripress.com/aml}

present. Although the present technology mainly uses polymer electrolyte membrane, some researches are still required in the membrane technology for minising methanol cross-over. All these factors are responsible for the poor performance of the DMFC due to the poor kinetics at the anode electrodes. From the present study, it is propose to prepare some more effective hybrid support materials including a hybrid of N-rGO and carbon nanofibers, $\mathrm{NrGO}$ and $\mathrm{N}$ doped CNTs for Pt based alloy nanoparticles including 3-d transition metals as well as $\mathrm{Ru}$ and $\mathrm{Pd}$ as anode electrodes to enhance the overall electrochemical activity of MOR and other alcohols. Further as shown in the research work done by Jiang et. al. [71] and $\mathrm{Li}$ et. al. [72-74] on mesoporous metallic Ir nanosheets, $\mathrm{Pd}-\mathrm{Pt}$ bimetallic nanodendrites, nanoporous metals and alloys $(\mathrm{Cu}, \mathrm{Ru}, \mathrm{Rh}, \mathrm{Pd}, \mathrm{Pt}, \mathrm{Au}$ etc and their alloys) all having high surface area, large pore volumes, easing mass transport of reactants and providing high accessibility to catalytically active metal surface could be supported on different hybride nanocomposites including NrGO-CNTs, NrGO-CNFs, rGO and carbon quantum dots and so on for the preparation of new anode electrocatalysts having much better electrochemical activity, stability and durability for MOR in a DMFC and for various practical applications including Li-ion batteries mobiles and other portable devices.

\section{Acknowledgements}

All the research work reported in this review article was carried out by $\mathrm{RB}$ during her Ph.D thesis and funded by CSIR, New Delhi, India under the CSIR-Emeritus Scientist Scheme sanctioned to SKS. The research facilities provided by the Director, CSIR-NPL is gratefully acknowledged for carrying out the present work. Special thanks are due to Dr SP Singh, who is also the co-author of many of our joint publications for scientific discussions and guidance from time to time. Sincere thanks are due to Dr. Nahar Singh, Mr. Naval Kishore Upadhyaya \& Mr Baijnath, Mr. K. N. Sood, Mr. M. Sarvanan, Ms Shweta Sharma and Dr. Priti Singh for their help in atomic absorption spectroscopy analysis of various electrocatalysts and raw materials prepared in the present work using XRD, SEM, FESEM, Raman spectroscopy and cyclic voltammetry measurements.

\section{Keywords}

Direct methanol fuel cells, electro-catalysts, support materials, methanol electro-oxidation, electrochemical properties.

\section{Received: 20 August 2020}

Revised: 22 November 2020

Accepted: 27 November 2020

\section{References}

1 Sharma, S.; Pollet B.G.; J. Power Sources, 2012, 208, 96.

2 Gottesfield, S.; Wilson, M.S.; New Trend Electrochem Technol, 2000, 1,487

3 Takasu, Y.; Fujiwara, T.; Murakami, Y.; Sasaki, K.; Oguri, M.; Asaki, T.; Sugimoto, W.; J. Electrochem Soc, 2000, 147, 4421.

4 Huang, H.; Wang, X.; J. Mater. Chem. A, 2014, 2, 6266.

5 Li, L.; Xing, Y.; Energies, 2009, 2, 789.

6 Li, L.; Xing, Y.; J. Phys Chem C, 2007, 111, 2803.

7 Rodriguez, J. R., Feliex, R. M.; Reynoso, E. A.; Gochi-Ponce, Y.; Gomez, Y. V.; Moyado, S. F.; Alonso-Numez, G.; J. Energy Chem, 2014, 23, 483 .

8 Xu, M. W.; Su, Z.; Weng, Z. W.; Wang, Z. C.; Dong, B.; Mater Chem Phys, 2010, 124, 785 .
9 Jha, N.; Mohana, A. L.; Shaijumon, M. M.; Rajalakshmi, N.; Ramaprabhu, S.; Int. J. Hydrog Energy, 2008, 33, 427.

10 Wu, G.; Xu, B. Q.; J. Power Sources, 2007, 174, 148.

11 Wang, D.; Liu, Y.; Huang, J.; You, T.; J. Colloid Interface, 2012 367, 199 .

12 Calderon, J. C.; Garcia, G.; Calvillo, L.; Rodriguez, J. L.; Lazaro, M. J.; Pastor, G.; Appl Cat B Environ, 2015, 165, 676.

13 Huang, H.; Sun, D.; Wang, X.; Chin Sci Bull, 2012, 57, 3071.

14 Ojani, R.; Raoof, J. B.; Goli, M.; Valiollahi, R.; J. Power Sources, 2014, 264, 76.

15 Kepeniene, V.; Yamasiunaite, L. T.; Jablonskiene, J.; Semasko, M. Vaiciuniene, J.; Vaitkus, R.; Norkus, E.; Mater Chem Phys, 2016, 171, 145.

16 Yang, Y.; Cheng, P.; Huang, S.; J. Alloys Comp, 2016, 688, 1172.

17 Hao, Y.; Wang, X.; Zheng, Y.; Shen, J.; Yuan, J.; Wang, A.; Niu, L.; Huang, S.; Electrochim Acta, 2016, 198, 127.

18 Dong, L.; Reddy, R.; Gari, S.; Li, Z.; Craig, M.M.; Hou, S.; J. Phys Chem C, 2011, 115, 15639 .

19 Baronia, R.; Goel, J.; Tiwari, S.; Singh, P.; Singh, D.; Singh, S. P.; Singhal, S. K.; Int. J. Hydrog Energy, 2017, 42, 10238.

20 Woo, S.; Lee, J.; Park, S. K.; Kim, H.; Chung, T. D.; Piao, Y.; Curr. Appl. Phys, 2015, 15, 219.

21 Seselj, N.; Engelbrekt, C.; Zhang, J.; Sci. Bull, 2015, 60, 864.

22 Dong, L.; Gari, R. P. S.; Li, Z.; Craig, M. M.; Hou, S.; Carbon, 2010, 48, 781.

23 Kakaei, K.; Zhiani, M.; J. Power Sources, 2013, 25, 356.

24 Li, Y.; Gao, W.; Li, L.; Wang, C.; Ajayan, P. M.; Carbon, 2010, 48,1124

25 Baronia, R.; Goel, J.; Singhal, S. K.; J. Nanosci Technol, 2019, 19 4315.

26 Baronia; Goel, J.; Kaswan, J.; Shukla, A.; Singhal, S. K.; Singh, S. P.; Mater Renewable Sustainable Energy, 2018, 7, 27.

27 Chen, M.; Lou, B.; Ni, Z.; Xu, B.; Electrochim Acta, 2015, 165 , 105 .

28 Sharma, S.; Ganguly, A.; Papakonstaninuo, P.; Miao, X.; Li, M.; Hutchison, J. L.; Delichatsios, M.; Ukleja, S.; J. Phys Chem C, 2010, 114, 19459 .

29 Li, C. Z.; Wang, Z. B.; Sui, X. L.; Zhang, L. M.; Gu, D. M.; Carbon, 2015, 93, 105.

30 Xiao, P.; Zhao, Y.; Wang, T.; Zhan, Y.; Wang, H.; Li, J.; Thomas, A.; Zhu, J.; Chemistry, 2014, 20, 2872.

31 Zheng, Y.; Liu, J.; Liang, J.; Jaroniec, M.; Qiao, S. Z.; Energy Environ Sci, 2012, 5, 6717 .

32 Tian, J.; Ning, R.; Liu, Q.; Asiri, A. M.; Al-Youbi, A. O.; Sun, X.; ACS Appl Mater Interfaces, 2014, 6, 1011.

33 Baronia, R.; Goel, J.; Gautam, G.; Singh, D.; Singhal, S. K.; J. Nanosci Technol, 2019, 19, 3832.

34 Joghee, P.; Pylypenko, S.; Olson, T.; Dameron, A.; Corpuz, A.; Dinh, H. N.; Wood, K.; O’Niell, K.; Hurst, K.; Bender, G.; J. Electrochem Soc, 2012, 159, F 768.

35 Xiong, B.; Zhou, Y.; Zhao, Y.; Wang, J.; Chen, X.; Hayre, R. O.; Shao, Z.; Carbon, 2013, 52, 181.

36 Zhao, S.; Yin, H.; Du, L.; Yin, G.; Tang, Z.; Liu, S.; J. Mater Chem $A, \mathbf{2 0 1 4}, 2,3719$

37 Zhou, Y.; Holme, T.; Berry, J.; Ohno, T. R.; Ginley, D.; Hayre, R. O.; J. Phys. Chem. C, 2010, 114, 506.

38 Dikin, D. A.; Stankovich, S.; Zimney, E. J.; Piner, R. D.; Dommett, G. H. B.; Evmenenko, G.; Nguyen, S. B. T.; Ruoff, R. S.; Nature, 2007, 448, 457.

39 Niyogi, S.; Bekyarova, E.; Itkis, M. E.; McWilliams, J. L.; Hamon, M. A.; Haddon, R. C.; J. Am Chem Soc, 2006, 128, 7720.

40 Stankovich, S.; Dikin, D. A.; Dommett, G. H. B.; Kohlhas, K. M.; Zimney, E. J.; Stach, E. A.; Piner, R. D.; Nguyen, S. B. T.; Ruoff, R. S.; Nature, 2006, 442, 282.

41 Li, D.; Mullar, M. B.; Gilje, S.; Kaner, R. B.; Wallace, G. G.; Nat Nanotechnol, 2008, 3, 101

42 Zhang, M.; Li, Y.; Yan, Z.; Jing, J.; Chen, M.; Electrochim Acta, $\mathbf{2 0 1 5}, 158,81$

43 Zhang, M.; Xie, J.; Sun, Q.; Yan, Z.; Chen, M.; Jing, J.; Int. J. Hydrog Energy, 2013, 38, 16402

44 Ma, J.; Wang, L.; Mu, X.; Cao, Y.; Colloid Interface Sci, 2015 , 457, 102 . 
45 Woo, Kim Y. R.; Chung T. D.; Piao, Y.; Kim, H.; Electrochim Acta, 2012, 59. 509.

46 Baronia, R.; Tiwari, S.; Srivastava, A. K.; Singh, S. P.; Singhal, S. K.; Adv Mater Proc, 2016, 1, 14.

47 Li, C. Z.; Wang, Z. B.; Sui, X. L.; Zhang, L. M.; Gu, D. M.; RSC Adv., 2016, 6, 32290.

48 He, D. P.; Zeng, C.; Xu, C.; Cheng, N. C.; Li, H. G.; Mu, S. C.; Pan, M.; Langmuir, 2011, 27, 5582.

49 Nassr, ABAA; Sinev, I.; Grunert, W.; Bron, M.; Appl Catalysis B: Environ, 2013, 142, 849.

50 Xiong, W.; Mehrabadi, B. A. T.; Karakalos, S. G.; White, R. D.; Shakauri, A.; Kasak, P.; Zaidi, S. J.; Weidner, J. W.; Regalbuto, J. R.; Colon-Mercado, H.; Monnier, J. R.; ACS Appl Energy Mater, 2020, 3, 5487.

51 Ahmadi, R.; Amini, M. K.; Int. J. Hydrog Energy, 2011, 36, 7275.

52 Lin, Z.; Song, M. K.; Ding, Y.; Liu, Y.; Liu, M.; Wong, C. P.; Phys Chem Chem Phys, 2012, 14, 3381.

53 Vinayan, B. P.; Nagar, R.; Rajalakshmi; Ramaprabhu, S.; $A d v$ Funct. Mater., 2012, 22, 3519.

54 Zhang, X.; Yuan, W.; Duan, J.; Zhang, Y.; Liu, X.; Microelectron Eng, 2015, 141, 234 .

55 Jae, C. Y.; Sung, K. H.; Hyungsoon, I.; Moon, M.; Bok, J. G.; Woo, L. C.; Jeunghee, P.; Mi-Hee, C.; Jaephil, C.; Seok, K. H.; J. Phys Chem C, 2011, 115, 9451 .

56 Xiong, B.; Zhou, Y.; Zhao, Y.; Wang, J.; Chen, X.; O'Hayre, R.; Shao, Z.; Carbon, 2013, 52, 181.

57 He, D.; Jiang, Y.; Lv, H.; Pan, M.; Mu, S.; Appl Catalysis B: Environ, 2013, 132, 379.

58 Zhao, S.; Yin, H.; Du, L.; Yin, G.; Tang, Z.; Liu, S.; J. Mater. Chem A, 2014, 2, 3719.

59 Wang, C.; Ren, F.; Zhai, C.; Zhang, K.; Yang, B.; Bin, D.; Wang, H.; Yang, P.; Du, Y.; RSC Adv, 2014, 4, 57600

60 Sunitha, M.; Durgadevi, N.; Sathish, A.; Ramachandran, T.; J. Fuel Chem Technol, 2018, 46, 592.

61 Ramli, Z. A. C.; Kamarudin, S. K.; Nanoscale Res Lett., 2018, 13, 410.

62 Liu, H. S.; Song, C. L.; Zhang, L.; Zhang, J.; Wang, H.; Wilkinson, D. P.; J. Power Sources, 2006, 155, 95.

63 Kitchin, J. R.; Norskov, J. K.; Barteau, M. A.; Chen, J. G.; J. Chem Phys, 2004, 120, 10240

64 Vinayan, B. P.; Ramaprabhu, S.; Nanoscale, 2013, 5, 5109

65 Yano, H.; Kataoka, M.; Yamashita, H.; Uchid, H.; Watanabe, M.; Langmuir, 2007, 23, 6438.

66 Hakan, B.; Hasan, A.; Esra, K.; Sen, F.; Sci Rep, 2020, 10, 6114

67 Xiong, L.; Kanan, A. M.; Manthiram, A.; Electrochem Commun, 2002, 4, 898

68 Antolini, E.; Salgado, J. R. C.; Dos, Santos A. M.; Gonzalez, E. R.; Electrochem Solid-state Lett., 2005, 8, A226.

69 Galal, A.; Atta, N. F.; Hassan, H. K.; Int. J. Electrochem Sci, 2012, 7,768

70 Lin, Y.; Cui, X.; Yen, C. H.; Wai, C. M.; Langmuir, 2005, 21, 11474 .

71 Jiang, B.; Guo, Y.; Kim, J.; Whitten, A. E.; Wood, K.; Kani, K.; Rowan, A. E.; Henzie, J.; Yamauchi, Y.; J. Am Chem Soc., 2018, $140,12434$.

72 Li, C.; Iqbal, M.; Jiang, B.; Wang, Z.; Kim, J.; Nenjundan, A. K.; Whitten, A. E.; Wood, K.; Yamauchi, Y.; Chem Sci, 2019, 10, 4054.

73 Li, C.; Iqbal, M.; Lin, J.; Luo, X.; Jiang, B.; Malgras, V.; Wu, K. C. W.; Kim, J.; Yamauchi, Y.; Acc Chem Res, 2018, 51, 1764

74 Li, C.; Tan, H.; Lin, J.; Luo, X.; Wang, S.; You, J.; Kang, Y. M.; Bando, Y.; Yamauchi, Y.; Kim, J.; Nano Today, 2018, 21, 91.

75 Xu, J.; Liu, X.; Chen, Y.; Zhou, Y.; Lu, T.; Tang, Y.; J. Mater Chem, 2012, 22, 23659.

76 Huang, H.; Fan, Y.; Wang, X.; Electrochim Acta, 2012, 47,1486.

77 Qian, W.; Hao, R.; Zhou, J.; Eastman, M.; Manhat, B. A.; Sun, Q.; Gofourth, A. M.; Jiao, J.; Carbon, 2013, 52, 595.

78 Jablonskiene, J.; Kepeniene, V.; Matuseviciute, A.; Drabavicius, A.; Tamasaukaite-Tamasiunaite, L.; Norkus, E.; Chemija, 2015, 26, 159 .

79 Baronia, R.; Goel, J.; Singhal, S. K.; J. Nanosci Nanotechnol, 2019, 19,4315 .

80 Hummer's, W. S.; Offeman, R. E.; J. Am Chem Soc, 1958, 801339.
81 Karthikeyan, K.; Mohan, R.; Kim, S. J.; Appl Phys Lett., 2011, 98, 244101.

82 Alam, S. N.; Sharma, N.; Kumar, L.; Graphene, 2017, 6, 1.

83 Zaaba, N. I.; Foo, K. L.; Hashim, U.; Tan, S. J.; Liu, W. W.; Voon, C. H.; Procedia Engg, 2017, 184, 469.

84 Sreeprasad, T. S.; Maliyekkal, M. S.; Deepti, K.; Chaudhari, K.; Xavier, P. L.; Pradeep, T.; ACS Appl Mater Interfaces, 2011, 3, 2643.

85 Gluex, L.G.; Sacchi, B.; Peuvot, K.F.; Anderson, R. L.; Olsson, R.T.; Nanoscale, 2017, 9, 9562.

86 Zhuo, Q.; Gao, J.; Peng, M.; Bai, L.; Deng, J.; Xia, Y.; Ma, Y.; Zhong, J.; Sun, X.; Carbon, 2013, 52, 559.

87 Shin, H.; Kim, K. K.; Benayad, A.; Yoon, S. M.; Park, H. K.; Jung, I. S.; Jin, M. H.; Jeong, H. K.; Kim, J. M.; Choi, J. Y.; Lee, Y. H., Adv. Funct. Mater., 2009, 19, 1987.

88 Muszynski, R.; Seger, B.; Kamat, P. V.; J. Phys Chem C, 2008, 112, 5263.

89 Feng, H.; Cheng, R.; Zhao, X.; Duan, X.; Li, J.; Nat Commun, $\mathbf{2 0 1 3}, 4,1539$.

90 Krishna, R.; Fernandes, D.M.; Venkataramana, E.; Dias, C.; Freire, C.; Titus, E.; Mater Today Proc., 2015, 2, 423.

91 Kim, P.; Joo, J. B., Kim, W.; Kim, J.; Song, I. K.; Yi, J.; J. Power Sources, 2006, 160, 987

92 Ghorbani, M.; Abdizadeh, H.; Golobostanfard, M.R.; Proc. Mater Sci, 2015, 11, 326.

93 Mathur, R. B.; Chatterjee, S.; Singh, B. P.; Comp Sci Technol, 2008, 68, 1608 .

94 Lin, Z.; Song, M.; Ding, K. Y.; Liu, Y.; Liu, M.; Wong, C. P.; Phys Chem Chem Phys, 2012, 14, 3381

95 Woo, S.; Kim, Y. R.; Chung, T. D.; Piao, Y.; Kim, H.; Electrochim Acta, 2012, 59, 509.

96 Peng, X.; Zhao, Y.; Chen, D.; Fan, Y.; Wang, X.; Wang, W.; Tian, J.; J. Electrochim Acta, 2014, 136, 292.

97 Khan, I. A.; Qian, Y.; Badshah, A.; Zhao, D.; Nadeem, M. A.; ACS Appl Mater Interfaces, 2016, 8, 20793

98 Sun, J.; Ma, H.; Jiang, H.; Dang, L.; Lu, Q.; Gao, F.; J. Mater Chem A, 2015, 3, 15882

99 Du, X.; Luo, S.; Du, H.; Tang, M.; Huang, X.; Shen, P. K.; J. Mater Chem A, 2016, 4, 1579.

100 Song, S. Q.; Liang, Z. X.; Zhou, W. J.; Sun, G. Q.; Stergiopoulos, X. Q.; Tsiakaras, P.; J. Power Sources, 2005, 145, 495.

101 Biroju, R. K.; Rajender, G.; Giri, P. K.; Carbon, 2015, 95, 228.

102 Tamasauskaite-Tamasiunaite, L.; Radomskis, A.; Antanaviciute, K.; Jablonskiene, J.; Balciunaite, A.; Zieliene, A.; Int. J. Hydrog Energy, 2014, 39, 282.

103 Shen, J.; Yan, B.; Shi, M.; Ma, H.; Li, N.; Ye, M.; Mater. Res Bull. 2012, 47,1486

104 Liu, J. G.; Zhao, T. S.; Chen, R.; Wong, C. W.; Electrochim Commun, 2005, 7, 288

105 Kim, D.; Cho, E. A.; Hong, S. A.; Oh, I. H.; Ha, H. Y.; J. Power Sources, 2004, 130, 172.

106 Park, G. G.; Yang, T. H.; Yoon, Y. G.; Lee, W. Y.; Kim, C. S.; Int J. Hydrog Energy, 2003, 28, 645 .

107 Han, J.; Park, E. S.; J. Power Sources, 2004, 112, 477.

108 Ren, F. F.; Zhou, W.; Du, Y.; Yang, P.; Wang, C.; Xu, J.; Int. J. Hydrog. Energy, 2011, 36, 6414.

109 Zhanga, L. X.; Cheng, X.; Tua, H.; You, M.; Zhang, Y.; Fan, Q.; ECS Transactions, 2007, 11, 1347.

110 Rossmeisi, J.; Ferrin, P.; Tritsaris, G. A.; Nilekar, A. U.; Koh, S.; Bae, S. E.; Brankovic, S. R.; Strasser, P.; Mavrikakis, M.; Energy Environ Sci, 2012, 5, 8335

111 Lei, X. L.; Wu, M. S.; Liu, G.; Xu, G.; Ouyang, C. Y.; J. Phys. Chem A, 2013, 117, 8293.

112 Zhong, J.; Li, L.; Waqas, M.; Wang, X.; Fan, Y.; Oi, J.; Yang, B.; Electrochim Acta, 2019, 322, 134677.

113 Duan, W.; Li, A.; Chen, Y.; Zhao, K.; Liu, J.; Wang, J.; J. Nanoparticle Res, 2018, 20, 287.

114 Chen, D.; Zhao, Y.; Peng, X.; Wang, X.; Hu, W.; Jing, C.; Tian, S.; Electrochim Acta, 2015, 177, 86.

115 Sun, J.; Ma, H.; Jiang, H.; Dang, L.; Lu, Q.; Gao, F.; J. Mater Chem A, 2015, 3, 15992.

116 Khan, I. A.; Qian, Y.; Badshah, A.; Zhao, D.; Nadeem, M. A.; Appl Mater Interfaces, 2016, 8, 20793. 


\section{Advanced}

117 Wang, Y. X.; Zhou, H. J.; Sun, P. C.; Chen, T. H.; J. Power Sources, 2014, 245, 663.

118 Yilmaz, M. S.; Kaplan, B. Y.; Gursel, A.; Metin, O.; Int. J. Hydrog Energy, 2019, 44, 14184.

119 Hong, W.; Wang, J.; Wang, E.; Nano Res, 2015, 8, 2308.

120 Du, M.; Sun, J.; Chang, J.; Yang, F.; Shi, L.; Gao, L.; RSC Adv, 2014, 4, 42412 .

121 Ma, J.; Wang, L.; Mu, X.; Li, L.; Int. J. Hydrog Energy, 2015, 40, 2641.

122 Rajalakhmi, N.; Ramaprabhu, S.; Adv. Funct. Mater., 2012, 22, 3519.

123 Zhou, Y.; Neyerlin, K.; Olson, T. S.; Pylypenko, S.; Butt, J.; Dinh, H. N.; Gennett, T.; Shao, Z.; Hyare, R. O.; Energy Environ Sci, 2010, 3, 1437.

124 Kim, P.; Joo, J. B.; Kim, W.; Kim, J.; Song, I. K.; Yi, J.; J. Power Sources, 2006, 160, 987.

125 Peng, X.; Chen, D.; Yang, X.; Wang, D.; Li, M.; Tseng, C.; Panneerselvam, R.; Wang, X.; Hu, W.; Tian, J.; Zhao, Y.; ACS Appl Mater Inter, 2016, 8, 33673.

126 Ramachandran, K.; Mohanraj, V.; Kim, A. R.; Shanmugam, R.; Yoo, D. J.; Int. J. Hydrog Energy, 2019, 44, 21769.

127 Fang, M.; Wang, K.; Lu, H.; Yang, Y.; Nutt, S.; J. Mater Chem, 1982, 20, 1982.

128 Pongpichayakul, N.; Waenkeaw, P.; Jakmunee, J.; Themsirimongkon, S.; Saipamya, S.; J. Appl Elect, 2020, 50, 51.

129 Wang, Y.; Yang, S.; Li, S.; Tien, H.; Hsiao, S.; Liu, C.; Chang, K.; Ma, C.; Hu, C.; Electrochim Acta, 2013, 87, 261.

130 Yan, M.; Jiang, Q.; Zhang, T.; Wang, J.; Yang, L.; Lu, Z.; He, H.; Fu, Y.; Wang, X.; Huang, H.; J. Mater Chem A, 2018, 6, 18165.

131 Ferrari, A. C.; Robertson, J.; Phys Rev B, 2000, 61, 14095.

132 Schniepp, H. C.; Li, J. L.; McAllister, M. J.; Sai, H.; HerreraAlonso, M.; Adamson, D. H.; Prud'homme, R. K.; Car, R.; Saville, D. A.; Aksay, I. A.; J. Phys Chem B, 2006, 110, 8535.

133 Ma, Y.; Liu, Z.; Wang, B.; Zhu, L.; Yang, J.; Li, X.; New Carbon Mater, 2012, 27, 250.

134 Tengco, JMM.; Mehrabadi, BAT.; Zhang, Y.; Wongkaew, A.; Regalbuto, J.R.; Weidner, J.W.; et. al. Catalysts, 2016, 6, 83.

135 Saha, S.; Basu, A.; Das, D.; Ganguly, S.; Banerjee, D.; Kargupa, K.; Int. J. Hydrogen Energy, 2016, 14, 18545.

136 Huang, H.; Fan, Y.; Wang, X.; Electrochim Acta, 2012, 80, 118.

137 Ahmadi, R.; Amini, M. K.; Bennett, J. C.; J. Cat, 2012, 292, 81. 